\title{
Arms Diffusion and War
}

\section{Citation}

Bas, M. A., and A. J. Coe. 2012. “Arms Diffusion and War.” Journal of Conflict Resolution 56 (4) (May 21): 651-674. doi:10.1177/0022002712445740.

\section{Published Version}

doi:10.1177/0022002712445740

\section{Permanent link}

http://nrs.harvard.edu/urn-3:HUL.InstRepos:22547793

\section{Terms of Use}

This article was downloaded from Harvard University's DASH repository, and is made available under the terms and conditions applicable to Open Access Policy Articles, as set forth at http:// nrs.harvard.edu/urn-3:HUL.InstRepos:dash.current.terms-of-use\#OAP

\section{Share Your Story}

The Harvard community has made this article openly available.

Please share how this access benefits you. Submit a story.

Accessibility 


\title{
Arms Diffusion and War
}

\author{
Muhammet A. Bas and Andrew J. Coe* \\ Department of Government \\ Harvard University
}

\section{Accepted for Publication at the Journal of Conflict Resolution}

November 15, 2011

\begin{abstract}
We present a model of the relationship between the spread of new military technologies and the occurrence of war. A new technology could shift the balance of power, causing anticipatory war as one side tries to prevent the other from obtaining it. When one side already has it, war is more likely when the shift in power is large, likely, and durable. When neither side has it, war is more likely when the expected shift is asymmetric (e.g., one side is more likely to get it) and when the two sides fear that a war will occur once one of them has it. We illustrate the model with historical examples from the spread of firearms (the Musket Wars in pre-colonial New Zealand) and of nuclear weapons (the end of US nuclear monopoly, and the 1967 Six-Day War). A broader implication is that major power competition can unintentionally cause wars elsewhere.
\end{abstract}

*Comments are welcome and should be sent to mbas@gov.harvard.edu and acoe@fas.harvard.edu. We are grateful to Amy Catalinac, Alexandre Debs, Jeffry Frieden, Nuno Monteiro, Robert Powell, Jonathan Renshon, Kenneth Shepsle, and Jane Vaynman for their comments on earlier drafts of this paper. We also thank participants at the 2009 meeting of the Peace Science Society; the IICAS PIA \& IR/PS ILAR $2009-10$ Joint Speaker Series at the University of California, San Diego; the Peter D. Watson Seminar Series at the University of Rochester; and the International Relations Workshop at Yale University, where we presented earlier versions of this paper. 


\section{Introduction}

Sitting at his desk in June of 1946, President Harry S. Truman wrote a note to himself: "Get plenty of Atomic Bombs on hand - drop one on Stalin, put the United Nations to work, and eventually set up a free world." ${ }^{1}$ Though the United States was then the sole possessor of nuclear weapons, Truman was well-aware that the Soviet Union was hard at work trying to copy the US invention, and that other states might follow suit. Indeed, only three years later, the Soviets would test their own atomic bomb, to Truman's great dismay. Yet Truman did nothing to stop it. Why?

The invention of new military technology is often followed by its diffusion around the world, and the introduction of the associated weapons into new locales is sometimes, though not always, attended by war. The spread of firearms to pre-colonial populations in the 18th and 19th centuries was concomitant with intense warfare among these groups, and the spread of nuclear weapons in the 20th and 21st centuries has also been marred by occasional wars. Were some of these wars caused by arms diffusion? If so, why did wars result in some cases but not others? How does the occurrence of war depend on the characteristics of the new weapons, and of the states to which they could spread? In particular, why was Truman content to bide his time while the Soviets got the bomb?

We explore these questions using a game-theoretic model of bargaining between two states in an environment in which new technologies are spreading. ${ }^{2}$ In the model, the acquisition of a new technology can shift the balance of military power between the two states. The likelihood of a state acquiring the new technology depends on its technological sophistication and its competence in espionage; the magnitude of the resulting shift depends on the specific technology and on the pre-existing military capabilities of the two states. Over time, a state

\footnotetext{
${ }^{1}$ The quote is taken from Trachtenberg (2007).

${ }^{2}$ We use "states" as a shorthand for organized groups, which are assumed to be unitary actors, whether they be nations or, as in one of our illustrative cases, tribes.
} 
may become more likely to acquire a particular technology, as the weapons' external spread, the state's spying efforts, and/or its internal development progress. And the introduction of new technologies may recur over time.

We find that states' inability to commit to not taking advantage of their new weapons can, under certain conditions, lead to a preventive war aimed at stopping a state from getting the new technology. States' expectations about the future are critical in determining whether war occurs. We show that war is more likely when the expected shift in relative power is large, likely, and durable, in line with the arguments of scholars of the preventive motivation for war (Taylor, 1954; Levy, 1987; Copeland, 2000; Levy, 2008). More surprisingly, we find that war can occur when neither, one, or both have acquired a new technology: the commonsense intuition that the preventive motivation for war will be highest when one state, but not the other, possesses the new weapons is true only under certain conditions.

We also demonstrate that preventive war is more likely when states anticipate a greater probability of war occurring in the future. Scholars of preventive war have long argued for this proposition, but it has not appeared previously in the bargaining literature on war. ${ }^{3}$ This is because previous models of shifting power assume that all future shifts in the balance of power will favor the same state. This is unrealistic with respect to arms diffusion; we relax it and find that the fear of future wars is a rational response to the possibilities created by the spread of new weapons.

We illustrate the model by applying it to several examples drawn from the history of the spread of firearms and of nuclear weapons. The introduction of each of these technologies is commonly understood to have been highly consequential for states' military capabilities, and so each is a prime candidate for generating preventive wars or the consideration thereof

\footnotetext{
${ }^{3}$ Based on his model of bargaining in the face of shifting power, Fearon (1995) shows that "the declining state attacks not because it fears being attacked in the future but because it fears the peace it will have to accept after the rival has grown stronger" (p. 406). A similar result follows from the model of shifting power given in Chapter 4 of Powell (1999).
} 
by states. We first look at the introduction of firearms to Maori tribes in New Zealand in the early 19th century, which was followed by the aptly named "Musket Wars." This series of unusually intense conflicts was initially characterized by tribes with newly acquired muskets attempting to destroy or enslave tribes without muskets - for preventive reasons, we will argue. Next, we examine the end of US nuclear monopoly, with the spread of nuclear weapons to the Soviet Union in the late 1940s. Our model suggests, and there is some evidence to support, that US hesitation to forcefully protect the monopoly was driven in part by the (violated) expectation that it would be a long time before the Soviets could successfully copy the bomb, in contrast to other accounts of this period that emphasize US lack of preparedness for or moral qualms about war. Finally, we turn to the 1967 SixDay War, between Israel and Egypt (among others). Our model predicts that preventive motivations with respect to Israel's nuclear program should have played a part in the origins of the war, supporting a recent and controversial line of historical work on this case.

Our model contributes to the formal literature that explains war with recourse to commitment problems arising from exogenous shifts in the balance of power. ${ }^{4}$ Existing models in this literature treat shifts in the balance of power as deterministic and perfectly anticipated, whereas our model allows shifts to be stochastic and hence uncertain (Fearon, 1995; Powell, 1999, 2009). This gives rise to empirical implications different from those of the deterministic models: states' war decisions turn on expectations about future shifts rather than the shifts that will actually occur, and so states may sometimes consider or launch preventive attacks even when no shift later occurs, and they may forego prevention even when a large shift later occurs.

Our work is also related to models of endogenous shifts in the balance of power due to

\footnotetext{
${ }^{4}$ For a general characterization of commitment problems, see Powell $(2004,2006)$. The seminal categorization of the rational causes of war is Fearon (1995). For a recent review of the formal literature on the causes of war, see Jackson and Morelli (2009a).
} 
arming (Powell, 1993; Meirowitz and Sartori, 2008; Baliga and Sjöström, 2008; Jackson and Morelli, 2009b; Debs and Monteiro, 2010). In particular, Baliga and Sjöström (2008) and Debs and Monteiro (2010) deal explicitly with the situation in which one state has the option of investing in acquiring a new military technology. Both models allow only one opportunity for the balance of power to shift, whereas our model allows both multiple opportunities for a given shift and multiple shifts as first one side, then the other tries to acquire a new technology. The cost of this additional generality is that, for tractability, we assume the shifts are exogenous, and as a result cannot assess the role of secrecy and ambiguity in a state's decision to pursue the new technology, which is the central concern of the cited models. However, we can study the role of secrecy about the progress a state is making toward acquiring a new technology, given that its decision to do so is known. In so doing, we shed light on an aspect of secrecy ignored by those models. ${ }^{5}$ Additionally, we can analyze the situation in which neither side has the technology and also study the effects of recurring technological diffusion. We thus view our work as complementary to prior efforts.

Finally, our study is more loosely related to a line of research focused on the determinants of successful incorporation and application of new technology by nations' militaries. Most recently, Horowitz (2010) offers a theory of diffusion based on states' financial and organizational capacities for adopting innovations. ${ }^{6}$ Our focus is not on the causes of diffusion, but rather its effects, and specifically its potential to cause preventive wars as one side tries to stop the other from successfully adopting a new technology. We parameterize the ability of states to copy a new technology, and then study how the value of this parameter affects the occurrence of war, while the research of Horowitz (2010) and others is concerned with

\footnotetext{
${ }^{5}$ In the models of Baliga and Sjöström (2008) and Debs and Monteiro (2010), a proliferant may have incentives to hide the existence of its program, but once the other side is aware of it, there is no further gain from secrecy because the game is effectively over - the proliferant is only allowed to have one try at developing the weapons in these finite-time models.

${ }^{6}$ This research extends earlier work on the determinants of successful military innovation, such as Posen (1984) and Rosen (1991).
} 
determining the value of this parameter for particular states at particular times.

In the next section, we describe the model and the assumptions we make. Section 3 characterizes the equilibria of the model and derives comparative statics. We then turn to the historical illustrations in Section 4, and Section 5 concludes.

\section{Setup of the Model}

We model the interaction between two states (or groups), $A$ and $B$, as they bargain over the division of an infinite flow of benefits, represented by the unit interval. The players alternate in discrete time between making and responding to proposals for revision of the status quo over the course of potentially infinitely many periods, with one offer per period. If the receiving player accepts the proposal, the revision is implemented immediately. If he rejects the offer peacefully, the status quo division is maintained. Finally, the receiving player can respond by starting a war, in which case the game ends with a costly lottery. ${ }^{7}$ The value of this lottery to each player depends on the balance of military power between them, represented by $A$ 's probability of victory in war. The winner receives the entire stake in this and all future rounds; the loser gets nothing. Regardless of who wins, each player pays a positive cost, $c_{A}$ and $c_{B}$ respectively, in this and all future periods, which represents the destructiveness of the war. ${ }^{8}$

In any given round, a peaceful response to an offer (whether acceptance or rejection) is

\footnotetext{
${ }^{7}$ This model, like those following Fearon (1995) in the bargaining theory of war, is inspired by the model of bargaining analyzed in Rubinstein (1982) and extended to include outside options (such as war) in Binmore, Rubinstein and Wolinsky (1986).

${ }^{8}$ We could also give the players the option of launching a limited (i.e., non-game-ending) attack aimed at temporarily lessening the probability of diffusion to the attacked side. Whether such an attack was preferred to a decisive preventive war in equilibrium would depend only on its relative cost-effectiveness - a limited attack would presumably be less destructive, but might have to be repeated over time, and might be more or less likely to succeed than a full-on war. However, costly fighting, whether limited attack or decisive war, would occur for the same reasons as those we identify here, so we ignore the possibility of a limited attack for simplicity.
} 
followed by a move by Nature which determines whether a new military technology diffuses to each player. In the Maori case, this can be thought of as the arrival (or not) of a European ship bearing firearms for trade; in the case of the initial spread of nuclear weapons, this is the success (or not) of the Soviet Union's development program. We assume that this process is exogenous - the players have no control over the occurrence of diffusion.

This assumption requires some justification. For it to be a reasonable approximation, two conditions must be met: first, the cost in terms of resources of acquiring the new technology must be outweighed by the benefits, and second, agreements by which the players avoid both diffusion and war via arms control must be unenforceable. The first condition means that the new technology cannot be too expensive relative to the gains it brings in terms of the acquiring player's bargaining power over the interests at stake between the players. Certainly, this condition holds in many empirical cases, including the three discussed in the next section. The Maori tribes, and the Soviet Union and Israel, had much to gain over their adversaries from acquiring firearms and nuclear weapons, respectively. For the Maori, firearms were cheap as Europeans were willing to trade them for goods the Maori had in abundance. And the Soviet Union's size and Israel's wealth meant that each could afford to devote the necessary resources to developing nuclear weapons.

The second condition means that the players cannot monitor each other's attempts to acquire the new technology well enough to prevent cheating on an arms control agreement. This condition also holds in many empirical cases, including the three discussed here. Once European ships had landed at a particular point along the coast, nothing could be done to stop the nearest tribe from obtaining firearms, and there was no way to anticipate these landings. And the US and Egyptian capabilities for monitoring the Soviet and Israeli nuclear programs (respectively) were quite rudimentary, as we will document in the next section. Thus, both conditions are met in many empirical cases and thus, for these cases, our as- 
sumption of exogenous diffusion is reasonable. ${ }^{9}$

If a player receives the technology, the balance of power shifts. Before either has the technology, the balance of power ( $A$ 's probability of victory in war) is $p_{00}$; when $A$ has it but $B$ does not, the balance is $p_{10}$ and similarly for $p_{01}$; and when both have it, the balance is $p_{11}$. Naturally, we assume that $p_{01}<p_{00}<p_{10}$ and $p_{01}<p_{11}<p_{10}$, so that unilateral possession of the technology is advantageous in war, relative to mutual acquisition or mutual lack of the technology. However, we allow $p_{00}$ to differ from $p_{11}$. If, for example, state $A$ has conventional forces superior to those of state $B$, but both have acquired nuclear weapons, then conventional arms may be of reduced importance in determining the overall balance.

We assume that the balance of power (variously $p_{00}, p_{10}, p_{01}$, and $p_{11}$ ) is also exogenous: the division of the flow of benefits does not affect it and the players cannot otherwise alter it. This allows comparison of our results with the extant literature on exogenous shifts in power, and preserves the model's tractability. Substantively, it means that we are assuming that measures to affect the balance of power-principally arming or transfers of resources (e.g., territory) that affect the balance - are unavailable, insufficiently effective, or too costly to be used by the players.

This assumption also merits some justification. First, consider arming. We will show below that only new technologies that have a sufficiently large effect on the balance of power might cause war. When this effect is large enough, additional arming by one side will not be enough to counteract the shift in the balance that occurs when the other obtains the

\footnotetext{
${ }^{9}$ Baliga and Sjöström (2008) and Debs and Monteiro (2010) endogenize a player's choice of whether to attempt to acquire nuclear weapons, and show that this can lead to equilibria where the player mixes over attempting and not, and the other player mixes over attacking and not. That is, equilibrium behavior may result in uncertainty over whether a nuclear program exists. However, this did not occur in the historical cases we consider: the US knew with certainty about the Soviet nuclear program, and Egypt knew about Israel's nuclear program, long before either program was successful. The key uncertainty in these cases is about the progress a state is making, not about whether it is trying. Our model incorporates this uncertainty, since success in acquiring the new technology is stochastic and may take many rounds of attempts, but we must abstract away from the choice over whether to keep trying for the sake of tractability.
} 
new technology. This held for all three of our examples from the history of the diffusion of firearms and nuclear weapons, and probably more generally for such consequential technologies. A Maori tribe without firearms could not muster enough additional manpower and crude weapons to maintain the balance against another that had acquired guns; the United States and Egypt could not sustainably arm themselves sufficiently to preserve the balance of power against the Soviet Union's or Israel's acquisition of nuclear weapons. The implication is that in the cases where our theory predicts war, compensatory arming will not suffice to prevent the anticipated shift in power that causes it. By contrast, for less consequential technologies, arming might suffice to counteract the anticipated shift, but our theory would predict peace in those cases anyway.

Second, consider transfers of resources. These would have to be conceded by the side that expected the balance of power to shift in its favor due to diffusion, to the side that expected to be disadvantaged. For this reason and unlike arming, the transfers could not be made after diffusion had occurred, because, as we show in Proposition 1 below, after diffusion the disadvantaged side would not have a credible war threat and so could not then coerce the advantaged side into making the concession. By contrast, transfers made before diffusion had occurred would not eliminate the anticipated shift in the balance of power due to diffusion - they would simply alter the baseline balance of power from which the players start. Thus, after the transfer was made, the same side would still expect to be disadvantaged by diffusion, and would demand yet another transfer as compensation to avoid war. For technologies whose diffusion would substantially alter the prior balance of power, the necessary transfers would be large and would quickly threaten the continued existence of the conceding side, and thus would not be made. The smaller transfers necessary to compensate for a less consequential technology's diffusion might be agreeable, but again, our theory predicts peace in these cases anyway. Thus, incorporating arming, transfers, or both into our model would not alter the main qualitative results of our analysis. 
The probability of diffusion depends on whether the other state has acquired the technology. When neither has it, $A$ 's probability of receiving it in the next round is $\lambda_{A}$, and similarly for $\lambda_{B}$. These are allowed to differ as a proxy for different levels of susceptibility to diffusion between the two states. For example, two states with economies of differing technological sophistication may have different probabilities of initial diffusion. If $A$ already has the technology, then the probability that $B$ will receive the technology in the next round is $\lambda_{A B}$, and similarly for $\lambda_{B A}$. We assume $\lambda_{A B} \geq \lambda_{B}$ and $\lambda_{B A} \geq \lambda_{A}$ : once one state has the technology, the other state is (weakly) more likely to receive it. This is plausible because the latter state now knows the technology is available and feasible and this may guide its efforts to duplicate it. Moreover, once one state has the technology, the other may employ espionage against the former and eventually steal the technology.

As a simplification, we typically assume that the various $\lambda$ 's do not change over time. That is, if a player does not receive the new technology in this round, then his chance of acquiring it in the next is the same, so long as the other player does not receive it in this round. So, the per-period chance of diffusion is not cumulative, even though the ex ante probability of diffusion occurring over the next several periods in increasing in the number of periods considered. This assumption is less applicable in the case of the spread of nuclear weapons. We relax it in Section 3.3, allowing $\lambda$ to increase over time, and discuss the differences this introduces.

Finally, we assume that there is only one new technology available. That is, once a player has received the technology, there is no other new technology to be acquired that could again shift the balance in his favor. This assumption greatly simplifies the exposition of the analysis, but it is unrealistic. We show in the appendix that relaxing this assumption does not alter the qualitative character of our results.

A player's utility is assumed to be linear in present consumption, defined as the player's 
share of the contested stake. Settlements are labeled by the share going to $A$ : the settlement in which $A$ receives $q$ and $B$ receives $1-q$ is called $q$. The players are assumed to discount future consumption at a common rate of $\delta<1$ per period. Players' preferences and all the exogenous parameters of the game are common knowledge.

\section{Equilibrium Analysis}

We use backward induction to find the subgame perfect equilibria (SPE) of the model, which requires players' strategies to be optimal in every subgame. We will show that the subgame in which both players have the technology, which we term "mutual armament," has a unique equilibrium outcome given the status quo division with which the players start. We then turn to the prior subgame in which one player has the technology but the other does not, called "diffusion." 10 We establish the conditions under which war occurs in SPE, and derive comparative statics for the various parameters. Next, we relax the assumption that the probabilities of diffusion are constant, analyzing the case in which they increase over time. Finally, we analyze the first subgame, in which neither player has the technology, which we label "introduction." Proofs of all the propositions are in the appendix.

\subsection{Mutual Armament Subgame}

We begin with the subgame where both players have the technology. Proposition 1 characterizes the unique outcome of any SPE of this subgame. This result is essentially identical to the results from the standard models of shifting power for the equilibrium outcome once the shift has occurred, so we only remind readers of the intuition (Fearon, 1995; Powell, 1999).

\footnotetext{
${ }^{10}$ We only give a proof for the case where $A$ has the technology but not $B$. The analysis for this subgame is mirrored by that for the subgame where $B$ but not $A$ has the technology, and can be obtained by switching labels.
} 
Proposition 1. Suppose that both players have the technology and that the status quo division is $q$. No war will occur. If $q<p_{11}-c_{A}$, then a permanent revision to $q^{\prime}=p_{10}-c_{A}$ will be immediately agreed. If $q>p_{11}+c_{B}$, then a permanent revision to $q^{\prime}=p_{11}+c_{B}$ will be immediately agreed. If $q \in\left[p_{11}-c_{A}, p_{11}+c_{B}\right]$, there will be no revisions.

Intuitively, once both players have the technology, there is no longer any uncertainty or any possibility of a future shift in the balance of power. The players can thus find a settlement that both prefer to war, and peace will prevail. Furthermore, aside perhaps from a single, immediate revision to bring the status quo division of the disputed stake into line with the balance of power, there is no cause for further revisions. The key comparative static is that the higher $p_{11}$ is, the better $A$ (and the worse $B$ ) will expect to do once both players have the technology.

\subsection{Diffusion Subgame}

Backing up, we assume that $A$ has the technology, but $B$ does not. Proposition 2 characterizes the unique outcome of any SPE of this subgame. ${ }^{11}$ As we will explain, the mechanism that leads to war here is the same as in the standard models of shifting power, but the interpretation is different.

Proposition 2. Suppose player $A$ has the technology, but $B$ does not. If $p_{10}-c_{A}+$ $\frac{\delta}{1-\delta} \lambda_{A B}\left(p_{10}-p_{11}\right)>1+\frac{\delta}{1-\delta} \lambda_{A B}\left(c_{A}+c_{B}\right)$, then there is war. Otherwise, there is peace, and at most one revision to the status quo, which is immediately agreed.

\footnotetext{
${ }^{11}$ We assume that $B$ makes the first offer in this subgame, so that $A$ might attack $B$ before he has a chance of receiving the technology. If instead $A$ made the first offer and the parameters were such that $A$ should attack $B$ to prevent him from acquiring the technology, $A$ would have to wait until the next round to do so, during which time Nature might bestow the technology on $B$, thus rendering the game peaceful by Proposition 1. This is a somewhat artificial possibility generated by the alternating-offers bargaining protocol: it is akin to saying that preventive war might be averted because the side without the technology could receive it before the other side can mount an attack, even if the latter chose to do so immediately. Assuming that $B$ makes the first offer allows us to ignore it.
} 
The root cause of war is that $B$ faces a commitment problem. ${ }^{12}$ He is likely to receive the technology at some point in the future, and when he does, the balance of power will shift in his favor. By Proposition 1, he will then demand and receive a revision that will bring the status quo into line with the new balance of power, leaving him better off and $A$ worse off. $B$ cannot commit himself ahead of time to not taking advantage of the technology once he acquires it, so if he cannot buy $A$ off by compensating him for the adverse shift to come, then $A$ will start a war in order to prevent the shift.

Anticipating this, $A$ will demand a larger share of the stake now, as compensation for the adverse shift to come. The largest compensation $B$ could commit to would be to concede the entire stake to $A$ for every period until the shift occurs (after which $B$ would take advantage of the new balance of power and demand a revision). If the shift is sufficiently likely and sufficiently large, then even this compensation is not enough: $A$ would still prefer to go to war in order to stop $B$ from gaining an advantage. However, if the shift is not so likely or so large, then $B$ can successfully compensate $A$ and the game is peaceful.

War can occur in this subgame because $A$ has reason to fear the future: $B$ will eventually receive the new technology, and $A$ 's temporary advantage deriving from its sole possession of the technology will be lost. Whether the loss of this advantage will compel a preventive war depends on how large the anticipated loss will be. The condition for war given in Proposition 2 implies that war can only occur when the anticipated shift in power (i.e., $p_{10}-p_{11}$ ), is larger than the total cost of war $\left(c_{A}+c_{B}\right)$. If the shift is not this large, then war is so destructive that its costs outweigh the benefits to $A$ of locking in his temporary advantage.

\footnotetext{
${ }^{12}$ To obtain the analogous result for the subgame in which $B$ but not $A$ has the technology, we just switch labels, as in Proposition 3 below.

Proposition 3. Suppose player $B$ has the technology, but $A$ does not. If $1-p_{01}-c_{B}+\frac{\delta}{1-\delta} \lambda_{B A}\left(p_{11}-p_{01}\right)>$ $1+\frac{\delta}{1-\delta} \lambda_{B A}\left(c_{A}+c_{B}\right)$, then there is war. Otherwise, there is peace, and at most one revision to the status quo, which is immediately agreed.
} 
However, unlike in the standard models in Fearon (1995) and Powell (1999), even a very large shift in the balance of power due to the diffusion of the new technology is not sufficient to cause war. If the shift is larger than the costs, whether war occurs or not also depends on how likely the shift is to occur. It is clear from the condition in Proposition 2 that an increase in the likelihood of the shift $\left(\lambda_{A B}\right)$ makes war more likely. $A$ has more reason to launch a preventive war to the extent that his advantage will be lost sooner. But conversely, if the chances of $B$ acquiring the new technology are very low, then $A$ will not start a war even if diffusion would be highly consequential for the balance of power, because diffusion will not happen any time soon.

The implication is that whether war occurs or not depends not only on the shift in power that diffusion would bring, but also on $A$ 's expectations about how likely diffusion is to occur. We will delve further into this implication next.

\subsection{Cumulative Diffusion}

The analysis in the previous section assumed that the per-period probability of diffusion (e.g., $\lambda_{A B}$ ) is constant over time. In reality, diffusion is typically increasingly likely to occur over time. For example, the visits of the European traders to New Zealand became more frequent over time, yielding an increasing probability that some new tribe would gain access to muskets. And a state's efforts to acquire nuclear weapons usually have an increasing chance of success as time goes by and progress in indigenous development, external assistance, and/or espionage occurs. In this section, we study a variant of the model in which the probability of diffusion increases over time, and show that the corresponding incentives for preventive war also grow over time. We show that a state facing the possibility of diffusion to another might choose to delay a preventive attack, putting off the costs of war until the other side is close to acquiring the technology, even though this poses some risk of diffusion 
occurring unexpectedly early. The analysis also reveals why the acquiring state might conceal its progress in duplicating the technology.

Suppose as in the previous section that player $A$ has the new technology, but $B$ does not. ${ }^{13}$ The game here is identical to that of the previous section, except that $\lambda_{A B}$ is now an increasing function of time. To economize on notation, suppose that the game starts at time $t=0$, and that at time $t, \lambda_{A B}=\lambda_{t}$. We assume that $\lambda_{t}$ is strictly increasing for $t \in\{0, \ldots, n\}$ for some $n<\infty$, and is constant at $\lambda_{n}$ thereafter. $^{14}$

Proposition 4. Suppose player $A$ has the technology, but $B$ does not, and $p_{10}-p_{11}>c_{A}+c_{B}$. So long as $B$ does not get it in the meantime, the value of war relative to peace for $A$ increases over time until period $n$, and is constant thereafter.

As in the previous section, the requirement that $p_{10}-p_{11}>c_{A}+c_{B}$ ensures that there is at least some incentive for preventive attack: it means that the advantage $A$ has due to sole possession of the technology is large enough to make it worth contemplating a costly war to preserve it. If this condition didn't hold, $A$ wouldn't attack regardless of the value of $\lambda_{t}$ - even if it were 1 , so that $B$ was certain to get the technology if $A$ didn't act to stop it. Given the condition, the proposition shows that the case for $A$ to attack gets stronger as time passes and $\lambda_{t}$ increases.

[Figure 1 about here.]

Figure 1 illustrates the intuition for the result. The values of $\lambda_{t}$ control when $B$ is expected to get the new technology. If the first few values of $\lambda_{t}$ are low enough, $A$ will expect that it will be a long time before $B$ ends its monopoly and so will have little reason to worry about it. In particular, $A$ will not attack in the early periods because he would

\footnotetext{
${ }^{13}$ The results for the reverse assumption can be obtained by switching labels.

${ }^{14}$ These assumptions simplify the exposition but do not affect the qualitative character of the results, which can easily be extended to the case of non-decreasing and/or asymptotic $\lambda_{t}$.
} 
rather put off the costs of preventive war until a later date. However, there is a trade-off between avoiding the costs of war in the current period and taking the risk that $B$ gets the technology in the meantime. As time passes and $\lambda_{t}$ grows, it becomes more likely that $B$ will get the technology very soon, and $A$ has more cause to worry about the imminent loss of its advantage. If $\lambda_{t}$ gets high enough, those worries will overcome $A$ 's desire to postpone the costs of war and $A$ will attack.

An implication of this is that $B$ might get "lucky." That is, it might be that $B$ acquires the technology faster than expected, while $\lambda_{t}$ is relatively low, and before $A$ is stirred to act. This explains why states are sometimes surprised by diffusion, and why the state that already had the technology would "let it happen." In empirical cases where diffusion occurs without preventive war, the explanation could be that the costs of preventive war were too high, so that $A$ would not attack even if diffusion was imminent and would let diffusion occur. But our analysis suggests an alternative explanation: that $A$ would have attacked but missed its chance due to $B$ 's luck, and so had no choice but to tolerate the shift. We will develop this further in our discussion of the end of US nuclear monopoly.

The analysis also shows why a state trying to acquire the technology might conceal its progress. Especially for difficult technologies, concealment generates uncertainty on the part of the state that has it about when the other will get it and can thus lower incentives for prevention. To see why, consider two extreme cases. In the first, $A$ can perfectly observe $B$ 's progress. In the second, $A$ sees nothing until the shift occurs.

In the first case, since $A$ has the technology and knows the steps involved in its development, he will be able to tell exactly when $B$ 's acquisition is imminent. That is, he can watch as $B$ 's efforts progress and see when it reaches the verge of success. At that point, the probability of diffusion is 1 , and so $A$ has the strongest possible incentive to attack then, because if he does not, the balance of power will shift with certainty. Obviously this does 
not bode well for $B$. If $A$ chose to attack, then $B$ has no chance of acquiring the technology and enjoying the benefits of the resulting shift in power, and B will also have to pay the cost of war.

If instead $A$ couldn't observe anything, he would always be uncertain about how far $B$ was from getting the technology. He would have to use his own experience with the technology and his knowledge of $B$ 's technological sophistication to estimate the probability that $B$ would acquire the technology in the next period, for each period: that is, he would have to estimate the $\lambda_{t}$ 's. A more difficult technology would have more steps involved in its acquisition, more possibilities for wrong turns, and more opportunities for delay as various elements were mastered. It would thus lead $A$ to assign a more diffuse distribution over when $B$ might be successful. Individual values of $\lambda_{t}$ would be lower, and would rise more slowly in $t$. Certainly, $\lambda_{t}$ would not equal 1 in any period. Thus, at any time, the incentives for preventive attack would be lower than in the previous case at the (known by $A$ ) time at which diffusion was imminent.

It might be the case that the distribution was so spread out that $A$ would not ever feel an urgent need to attack, no matter how long it took $B$ to be successful. Or, consistent with Proposition 4, there might come a time when $A$ would think that diffusion was close enough (that is, $\lambda_{t}$ was high enough) to warrant preventive attack. But the time that would pass before that point would constitute time for $B$ to get lucky. Thus, relative to the first case, $B$ would have a higher chance of acquiring the technology and gaining the corresponding advantage, as a well as a lower chance of having to pay the cost of war.

Most empirical cases would fall somewhere between these two extremes. $A$ would have some ability to observe $B$ 's progress, and $B$ would have some ability to conceal its efforts. But the comparison of the two extremes makes clear why secrecy would be beneficial for $B$ 
(and harmful to $A$ ) and surveillance beneficial for $A$ (and harmful to $B$ ). ${ }^{15}$

Previous models of shifting power did not produce these results because they assume either that the shift is deterministic or that it can only occur at one point in time (Fearon, 1995; Powell, 1999; Baliga and Sjöström, 2008; Debs and Monteiro, 2010). When this is true, $B$ has incentives to try to conceal the existence of its efforts at acquiring the new technology from $A$, but there is no progress to speak of, so that once $A$ knows of $B$ 's program, there is no more reason for secrecy. Either $A$ attacks or he doesn't-there is no possibility of watching and waiting to attack until $B$ is close to success, no possibility of $B$ getting lucky in the meantime, and no possibility of $A$ regretting its delay.

Our model explains why one state might simply watch and wait as another attempts to acquire a consequential new technology and to conceal its progress in doing so. The costs of preventive war are not worth suffering until diffusion is near. Because of this, the acquiring state will try to conceal its progress, so that the watching state is never certain that diffusion is imminent, and might get lucky, successfully developing the technology before the watching state acts to stop it.

\subsection{Introduction Subgame}

Finally we turn to the subgame in which neither player has received the new technology. We first assume that the effects of the technology, should either or both players receive it, and

\footnotetext{
${ }^{15}$ The analysis is more complicated if $B$ can send a message about its progress to $A$. If the message is not independently verifiable by $A$, then it can only be informative in equilibrium if it varies in $B$ 's actual progress. Of course, $B$ should say that progress is slow regardless of the truth, in order to minimize the chance of a preventive attack. So the only equilibrium is a pooling one, in which $B$ always sends the same message, and it is thus ignored by $A$.

In the other extreme, if the message is perfectly verifiable (e.g., $B$ allows comprehensive inspections by $A$ ), then separation can occur in equilibrium. As time passes, if $B$ 's progress is slow enough, revealing this may be necessary to assure $A$ that diffusion is not imminent and prevent an attack. If instead $B$ 's progress is rapid enough, then revealing this would increase the chance of attack, so $B$ should reveal it later, if at all. The general conclusion, that $B$ should use concealment to delay preventive war, still holds.
} 
the probabilities of it diffusing to either or both players are common knowledge. Under this assumption, we show that the outcome turns on the expected shift in the balance of power and the probability of a preventive war occurring in the future. If these are large enough, then the player who expects to lose in the future may fight now to avoid the (expected) shift and risk of future war. We then discuss what happens when this assumption is relaxed, so that players are unable to perfectly forecast the "next" new technology. We argue that uncertainty about the technological future makes war in the introduction subgame less likely.

To state the main result, we need some additional notation. Let $\Delta p$ be the expected shift in the balance of power:

$$
\Delta p \equiv \lambda_{A}\left(1-\lambda_{B}\right)\left[p_{10}-p_{00}\right]+\left(1-\lambda_{A}\right) \lambda_{B}\left[p_{01}-p_{00}\right]+\lambda_{A} \lambda_{B}\left[p_{11}-p_{00}\right]
$$

This expected shift takes into account that, in the next period, $A$ could acquire the technology, $B$ could, or both could simultaneously. It can be thought of as a measure of asymmetry in the possible futures. If $\Delta p=0$, then the future is perfectly balanced; neither player expects an advantage. However, if $\Delta p>0$, then the future is expected to benefit $A$, and vice versa. The further $\Delta p$ is from zero, the more sharply the future favors one player over the other.

We will assume that $\Delta p \leq 0$, so that the balance of power is expected to move against $A$ (perhaps weakly). ${ }^{16}$ Let $V_{i j}^{A}(1)$ be the value $A$ receives in equilibrium and $W_{i j}^{A}$ be the war value $A$ would receive in the $i j$ subgame, where $i j \in\{01,10,11\}$, when the subgame is entered with $q=1$. Then $S_{i j}^{A} \equiv V_{i j}^{A}(1)-W_{i j}^{A}$ is the value of the $i j$ subgame over and above $A$ 's war value in that subgame, given that $A$ starts in possession of the whole stake. We call this A's "surplus."

The values of $S_{i j}^{A}$ are determined by Propositions 1 through 3, but we offer a few obser-

\footnotetext{
${ }^{16}$ The results are symmetric if we make the opposite assumption.
} 
vations about these values to guide the intuition. First, all these values are non-negative; since $A$ can always go to war, he would never accept less than his war value in any subgame. In fact, if war occurs in the $i j$ subgame, then $S_{i j}^{A}=0$. By contrast, $S_{i j}^{A}$ may be as large as $\frac{c_{A}+c_{B}}{1-\delta}$ if the $i j$ subgame is peaceful and $A$ captures the full surplus from avoiding war for the rest of the game. In fact, we know from Proposition 1 that $S_{11}^{A}$ is equal to this upper bound, because, upon entering this subgame holding the entire stake, $A$ will concede only enough to make $B$ indifferent between war and peace.

Finally, let $\mathbf{S}^{A}=\lambda_{A}\left(1-\lambda_{B}\right) S_{10}^{A}+\left(1-\lambda_{A}\right) \lambda_{B} S_{01}^{A}+\lambda_{A} \lambda_{B} S_{11}^{A}$. This is the expected surplus that $A$ will obtain if a shift occurs in the next round, given that a war does not occur in this round. It can be thought of as the reward to $A$ from not going to war now. Observe that $\mathbf{S}^{A}$ is smaller when war is more likely to occur in a future subgame - we will use this in interpreting the following proposition.

Proposition 5. Suppose neither player has the technology and $\Delta p \leq 0$. Then war will occur if and only if $p_{00}-c_{A}-\frac{\delta}{1-\delta} \Delta p>1+\delta \mathbf{S}^{A}$.

The proposition shows that whether war occurs depends principally on the relationship between the expected shift in power $\Delta p$ and the expected future surplus $\mathbf{S}^{A}$, since these will dominate the inequality for plausibly high values of the discount factor $\delta$. When $\Delta p$ is further from zero, $A$ expects the balance of power to shift more sharply against it. And when $\mathbf{S}^{A}$ is smaller, there is less and less reason to wait to fight, because the future offers $A$ little more than he would get from fighting then. This is most obviously the case if one or both of the diffusion subgames (where just one player has the technology) result in war- $A$ receives no surplus in such subgames.

The intuition for this result is that, if the future favors $B, B$ would prefer to do whatever he can to placate $A$, including conceding the entire stake, at least until a shift occurs. However, if the future looks bleak enough for $A$, then $B$ 's concessions prior to a shift and 
the value of the peace surplus $A$ would expect to capture in the future will not be enough to stave off a preventive attack by $A$. Put another way, the darker the future appears to $A$, whether because of a worse expected shift or a higher probability of later war or both, the more likely it is that $A$ would prefer to fight now.

This shows that the claim made by Levy (1987) and others, that the fear of future war can be a powerful motive for preventive attack, is right, at least in the context of arms diffusion. A might attack when neither state has the technology, in part because of a fear that if one or the other state got the technology first, it would then fight a war to prevent the other from succeeding it. Prior models of preventive war did not exhibit this phenomenon because they assumed that the shifts in the balance of power would always favor a particular side (Fearon, 1995; Powell, 1999). In equilibrium in these models, the favored side would have no incentives to launch a war, as it would expect its bargaining position to improve. As a result, the other side has no rational reason to fear future war. Our model implies otherwise because it allows for multiple shifts as first one side, then the other, obtains the new technology: opposing shifts create opportunities for both players to face incentives for preventive attack, and hence to rationally anticipate the possibility of future war.

In fact, any combination of war or peace in the various subgames can occur. Table 1 gives examples of plausible parameter values that lead to each possible combination of outcomes. Notice that we can find sets of parameter values that lead to war in the introduction subgame even when one or both diffusion subgames are peaceful.

This may seem a strange finding. Intuitively, we would expect that the most dangerous times are when one potential belligerent has the technology, but the other does not. The last three rows in Table 1 show that this is not necessarily the case. In Section 4, we will argue that this is not an artifact of the model, using the 1967 Six-Day War as an example in which war occurred before any of the belligerents had a (deliverable) nuclear weapon. 
[Table 1 about here.]

So far we have assumed that the players could confidently predict the effects of the "new" technology and the likelihood that either would acquire it. This might be the case when the players anticipate receiving a technology that external actors already possess and have had a chance to observe the technology in action. These observations would allow them to form expectations about the effects this technology might have on their situation. For example, we expect that Israel and Egypt prior to the 1967 War, having seen the effects of the acquisition of nuclear weapons by several other states, would have reasonable estimates of the effects of the introduction of nuclear weapons on the balance of power between them.

However, when players cannot observe the technology before acquiring it, they will likely be substantially uncertain about what it is and what its effects might be. At the opposite extreme to the confident forecasting assumed above, players may have little idea about what technology lies around the corner. We can model this as though there is a space of possible technologies, each defined by a particular set of parameter values for $\lambda_{A}, p_{10}$, and so on, and a distribution over these technologies that determines which is going to be discovered next. A variant of our model, in which the introduction of new technologies can recur over time and there is uncertainty about what technology comes next, is discussed in the appendix. Here, we sketch the intuition behind the main results.

Technologies that are highly consequential, in the sense of having large effects on the balance of power between two states, are rare. The "next" technology is much more likely to have modest effects on the balance of power, insufficient to cause war regardless of who has it and who doesn't. Thus, the expected value of $\Delta p$ over the distribution of technologies is relatively close to zero and, by Proposition 5, war will not occur. (Note that if $\Delta p$ is close enough to zero, the inequality in the proposition cannot be satisfied.) To put it in terms of one of our illustrative cases, suppose (counterfactually) that Israel and Egypt did not know 
that the "next" technology was nuclear weapons, or had some inkling of this but had not learned from observing previous proliferation what the effects on their own balance of power would be. Without any other information, they would likely assume that the effect of the next technology would be modest, since this is true for most new technologies, and hence the potential for either to acquire a new technology would not be enough to cause war.

This refines the intuition that preventive wars launched prior to either side acquiring a new technology should be rare. When neither has done so and there is no good information available about the next technology, uncertainty and the rarity of highly consequential technologies mean that there is little cause for preventive war. By contrast, when one side has developed a new technology, both sides can observe it and estimate its effects, and should those effects be large, war may result as one side tries to defend its monopoly. However, it may also be the case that, even though neither side has the technology, both know what the next technology is and that it will have large effects on their balance power. There would then be substantial incentives for war.

This argument carries implications for the war-proneness of different eras. In eras in which all states (either in the world or in some isolated region) possess roughly similar military technology, so that diffusion of the last highly consequential new technology is complete and the next new technology is unknown, wars due to the introduction and diffusion of new technologies will be rare. But in eras in which the next technology is known and consequential, such as the era of the spread of firearms from Europe or the current era of nuclear proliferation, wars due to the introduction and diffusion of that technology to new regions will be more common. We will return to this implication in the conclusion, as it has further ramifications for understanding the global externalities imposed by competition among the more technologically-advanced states of the world.

To summarize, we found that war could occur even before either side had the new tech- 
nology, and even if one or both situations where one side had it but the other did not would be peaceful. The introduction of a new technology is more likely to cause war when states can confidently estimate its effects, when it is expected to benefit one side asymmetrically, and when states expect that, upon acquiring the technology first, one or both states might attack the other to preserve its monopoly.

\section{Illustrations}

Next we offer three examples drawn from the histories of the spread of firearms and of nuclear weapons to illustrate the model. The Musket Wars, fought in New Zealand in the early 19th century after the introduction of firearms there, demonstrate the most basic intuitions of the model. The end of the nuclear monopoly, when the United States allowed the Soviet Union to acquire nuclear weapons without preventive attack, illustrates how a rise in the

probability of acquisition over time can result in peaceful diffusion if the acquiring state gets "lucky" and receives the technology earlier than expected. It also allows us to discuss the incentives for secrecy with respect to a state's progress at acquiring a technology. Finally, the 1967 Six-Day War is used to show that the preventive motivation for war can arise even when neither side has acquired the technology.

\subsection{The Musket Wars}

In the early 19th century, the northern coast of New Zealand became a favored stop for European trading and whaling ships. With more frequent European visits, the Maori tribes that populated the region began trading with the Europeans, and among other things, these tribes gained access to muskets for the first time in their history (King, 1997; Crosby, 1999). Equipped with this new technology, the northern tribes started to launch raids against 
the southern tribes that did not possess firearms. These raids marked the beginning of the "Musket Wars", the largest conflict ever fought on New Zealand soil (Belich, 1996). This bloody period of conflict lasted almost 30 years, reduced the native population of New Zealand by more than a quarter according to some estimates, shifted boundaries, and indirectly paved the way for large-scale European settlement in the 1840s (Belich, 1996; Crosby, 1999). ${ }^{17}$

Before the arrival of muskets, violence among Maori tribes was intermittent and of much lower intensity than that seen during the Musket Wars. Though there were long-term rivalries between many tribes, these only occasionally resulted in violence, and the clashes were usually localized, took place for short periods during the summer, and in many cases resulted in very limited casualties (King, 1997; Crosby, 1999). The Musket Wars, on the other hand, were marked by total warfare between tribes. Different periods of the wars witnessed the rise and dominance of tribes with firepower - e.g. Ngapuhi, Waitago, and Ngati Toa - in different regions of New Zealand, and the weakening, elimination, or forced migration of unfortunate neighboring tribes that lacked muskets.

Our model offers a clear explanation for why the northern tribes initiated this bloody warfare. This example corresponds to Case 4 in our Table 1, where acquisition of a new technology by a group creates a commitment problem with other groups that have not yet received the technology, and a preventive war results. In the Maori case, the selective diffusion of muskets resulted in a big shift in the balance of power relative to indigenous weaponry, and made the tribes equipped with muskets willing to launch a preventive war against those tribes that lacked the technology. In particular, the shift in the balance of capabilities was seen as temporary, as the tribes possessing firearms expected the other tribes to gain access to these weapons very soon, knowing that the Europeans would explore

\footnotetext{
${ }^{17}$ For different estimates of Maori population decline after contact with the Europeans, see Pool (1977; 1991).
} 
other opportunities for trade. This exacerbated the commitment problem, because the tribes with the muskets anticipated that, if they waited, their advantage would be lost and the opportunity it presented squandered. Attacking the tribes that lacked muskets was seen as a low-cost, effective strategy to maximize their long-term share of the existing resources on the island. ${ }^{18}$ In our model's terms, $\lambda_{A B}\left(p_{10}-p_{11}\right)$ was high enough relative to the size of the per period surplus from peace, $c_{A}+c_{B}$, so that it did not make sense for the tribes with firearms to agree to any concession: instead they sought to eliminate or conquer and enslave their opponents. ${ }^{19}$ Thus, our model suggests that the Musket wars were preventive in nature, as the high chance that other tribes of the island would soon acquire this weapon gave the already-armed tribes strong incentives to stop this shift in power from happening.

\subsection{The End of the Atomic Monopoly}

The Soviet Union's successful development of nuclear weapons, less than five years after the first appearance of that technology in war, fundamentally altered the course of the nascent Cold War, ending the US nuclear monopoly and resulting in 40 years of nuclear-enforced stalemate between the superpowers. At least in hindsight, the case for the US to launch a preventive war-before the Soviet Union could get nuclear weapons-seems substantial (Quester, 2000). So why didn't it? The answers debated in the literature focus mainly on the perceived costs of preventive war, but our model suggests an additional factor, rooted

\footnotetext{
${ }^{18}$ Using muskets to fight an enemy that lacked muskets did not require close contact with the enemy, and therefore reduced the cost of fighting for the attacker. Secondly, trade with the Europeans also introduced potatoes to the island as a durable food source, which made long range raids across the island less costly.

${ }^{19}$ One can also argue that it was probably not only their fear of other tribes gaining access to muskets, but also the additional uncertainty arising from the possibility of other, known or unknown, more advanced technologies being introduced to the island in the future by outsiders. Before their encounters with the Europeans, these tribes did not have any reasons to expect such changes, and $\lambda_{A}$ and $\lambda_{B}$ were practically zero. Once the possibility of large shifts became evident with the introduction of muskets, however, they now had to consider the possibility of other technologies entering the island in the future, changing the balance. In fact, during the later years of the Musket Wars, small cannons were used by some of the tribes. Some tribes also confiscated or rented European ships to use in their raids to other islands, or used European mercenaries in their raids (Crosby, 1999).
} 
in uncertainty about how fast nuclear technology would diffuse, that might explain the US hesitation.

Historians have documented serious consideration at high levels in the Truman administration of a preventive attack on the Soviet Union. ${ }^{20}$ Two explanations are commonly given for why the US elected not to do so. First, Buhite and Hamel (1990), Debs and Monteiro (2010), and Trachtenberg $(1988,2007)$ argue that, at the time, the US perceived the material costs of a preventive war to be so high that it would rather tolerate the certain loss of its monopoly than fight to preserve it. The crux of these arguments is that, in the critical period from 1945 to 1949, the US was ill-prepared to fight a war against the USSR: it had demobilized most of its military, especially in Europe where the USSR could retaliate devastatingly against a preventive attack; its nuclear stockpile and delivery capabilities were too small to cover the large Soviet target set; and it lacked the intelligence necessary to enable a more surgical preventive strike on the Soviet nuclear program. Thus, preventive war was just too expensive to be worthwhile.

While it is undoubtedly true that the lack of US preparations increased the material costs of fighting a preventive war, these arguments raise the question of why the US was so unprepared (Quester, 2000, ch. 2). When, in the aftermath of the Soviet nuclear test and soon after the start of the Korean War, the US commenced a military buildup, it was able greatly to strengthen its conventional forces in Europe and elsewhere and to expand its nuclear arsenal in just two years (Silverstone, 2007; Trachtenberg, 1988). This buildup could have been implemented over 1946-8, rather than 1950-2, if the US had chosen to do so, and would have substantially reduced the material costs of preventive war discussed above.

Following this line of reasoning, Quester (2000) and Silverstone (2007) argue that the material costs of preventive war are not sufficient to explain US hesitation. They offer an

\footnotetext{
${ }^{20}$ See Buhite and Hamel (1990), Quester (2000, ch. 4), Silverstone (2007, ch. 2), and Trachtenberg (1988, 2007).
} 
alternative explanation based on the moral costs of preventive war. According to this theory, American ideals at the time were inconsistent with an unprovoked attack on the Soviet Union that would likely result in the deaths of millions of civilians, and US decision-makers believed that the US public would therefore not support a preventive war, regardless of the strategic arguments for it.

Our model, like other models of shifting power in international relations, suggests that an examination of the costs of a preventive war, whether material or moral, may not suffice to explain the occurrence or absence of such a war, and by extension, of preparations for the war. Rather, whether war occurs depends not only on the costs of the war but also on expectations about the size, direction, and likelihood of future changes in the balance of power. Our model is unique in allowing us to analyze the incentives for war when there is uncertainty about when the balance will change.

There was widespread agreement on the part of US policy-makers that the arrival of a Soviet nuclear capability would eliminate a substantial US advantage, exacerbate US conventional weakness in Europe, and expose the US itself to the risk of a devastating surprise attack (Richelson, 2007; Silverstone, 2007; Trachtenberg, 1988). To put it in terms of our model, the perceived difference between $p_{10}$, the status quo balance of power, and $p_{11}$, the new balance that would obtain if a shift to nuclear bipolarity occurred, was large. Proposition 2 demonstrates that this heightens the incentives for preventive war.

Gordin (2009) and Richelson (2007) document great uncertainty on the part of the US as to when the Soviet Union would acquire the bomb. The US was deeply surprised by the first Soviet test. ${ }^{21}$ The consensus estimates of the US intelligence community, through the

\footnotetext{
${ }^{21}$ We focus on the period up until the first Soviet test as the clearest illustration of the model. The moment just after the Soviet Union had acquired the technology, but before it had weaponized and deployed it, might seem an opportune one for preventive attack. However, this vulnerability was recognized, and it was for precisely this reason that the test was delayed until the Soviet Union had sufficient fissile material for additional bombs (Quester, 2000, p. 133). Thus, we treat the US detection of the Soviet test in September of 1949 as the moment at which a large shift in $p$ occurred. This is consistent with our model, which assumes
} 
middle and late 1940s, asserted that the USSR would most likely test a weapon by 1953, with a low probability of a test occurring in 1952 or 1951; other influential analysts argued for much later dates. According to Gordin and Richelson, the error derived from exceedingly spotty information on the progress of the Soviet program, from ignorance of the degree of penetration of the US nuclear establishment by Soviet spies, and from a mistaken belief on the part of some analysts that the US had managed to corner the market for fissile material.

This uncertainty can be modeled according to the cumulative diffusion model from Section 3.3. The US assessed $\lambda_{t}$, the probability that the USSR would acquire the bomb in year t, as quite low during 1945-1950 and increasing slowly over 1951-1952, with higher probability from 1953 on. Proposition 4 suggests that the US could simply have been putting off the costs of preventive war until $\lambda_{t}$ was sufficiently high - that is, until the threat of Soviet acquisition was closer to imminent. ${ }^{22}$

Our model thus provides an explanation for why high-level US officials would advocate a massive new military build-up only after the first Soviet nuclear test (Trachtenberg, 1988). Before the test occurred, US policy-makers anticipated that the Soviet program was unlikely to achieve success for several more years. They thus had every reason to delay the large expenditures necessary to prepare for a war, as the US could count on the Soviets to avoid war until they had ended the monopoly. A "lucky" break for the USSR, owing to the unexpected successes of its spies and scientists, surprised the US and motivated many officials to conclude that the US had to be prepared for preventive war as well as a conventional defense of Western Europe (Trachtenberg, 1988). The high costs of such a war, though obvious, were nonetheless

that the change in the balance of power, once it begins, occurs too quickly for a state to preempt the change once it has been observed.

${ }^{22}$ While Gordin (2009) endorses the lack of preparedness as the most important factor in explaining the absence of a US preventive attack, observing that "the hawks never got very far, mostly because the military never expressed confidence that it had enough troops, planes, or (crucially) bombs actually to 'knock' out the Soviet Union" (pp. 60-61), he also mentions that the "lengthy estimate" of when the Soviet Union would get the bomb "discourage[d] a preemptive strike..." (p. 87). 
not sufficiently compelling to merit continued delay of rearmament. Indeed, as noted before, when the US finally did initiate a massive military buildup, it arrived at the desired level of military preparedness in just two years. Thus, there was no need to make preparations in the late 1940s, when US leaders still thought they had years before the Soviets got the bomb.

Our analysis also exposes the incentives for the USSR to conceal its progress. If it had made no effort to do so, the US could have more easily watched its program and might have attacked just before the USSR's program was successful, when the urgency of prevention would be highest. However, since the USSR took great pains to conceal its program, the US had to rely on highly uncertain estimates of Soviet science and espionage, leading to imperfect anticipation of the timing of the shift in power. The analysis in Section 3.3 shows that this reduces the incentives for war. The result was that the Soviets "got lucky" and were successful before the US expected, surprising it. ${ }^{23}$

To summarize, the model exposes an additional factor that may explain US hesitation in preventing the spread of nuclear weapons to the USSR and why the Soviets took care to conceal their progress. ${ }^{24}$ The model itself cannot adjudicate between the claim that the high costs of prevention, moral and/or material, were sufficient to cause US reluctance and the claim that the low US expectations of the speed of nuclear diffusion were also necessary. But

\footnotetext{
${ }^{23}$ The Soviet campaign of espionage gave the USSR good reason to think that the US estimate of its progress was lower than its own. If the US was unaware of Soviet spying, it would have a too-low estimate. If the US was aware, it would be feeding misinformation to the Soviets, which would slow the program down and thereby lower the US estimate of progress below that of the Soviets. Either way, the USSR had reason to continue to hide its actual progress.

${ }^{24}$ We note also that the pattern of concessions between the US and USSR during this period, at least as described by Trachtenberg $(1988,2007)$, is consistent with the implications of the model. Before it acquired nuclear weapons, the USSR was careful to avoid provoking the US to the point of starting a war, even while it consolidated its control over eastern Europe and even though the US had rapidly demobilized and removed its forces from western Europe. Once the USSR had deployed its own nuclear weapons, however, it became much more bellicose in its dealings with the West. Perhaps the clearest example of newfound Soviet confidence came in the form of approval and material support for North Korea's invasion of South Korea in 1950, and for its approval of China's entry into that war later in the year.
} 
it does show that the evidence typically given for a cost-based explanation for US hesitation is inconclusive. US lack of preparation for, and willingness to air moral qualms about, a preventive war is consistent both with an assessment that the costs would be too high, and with an assessment that it could afford to wait and see how the situation developed.

\subsection{The 1967 Six-Day War}

Between June 5 and June 10, 1967, Israel fought a short, intense war with Egypt, Syria, Jordan, and Iraq, in which Israel was eventually victorious, capturing territory from the first three opponents and seriously reducing the military forces of all four. Recent research into the history of the Six-Day War, based on newly declassified documents and new revelations from participants in the war, suggests that Israel's nuclear weapons program played a more important role in the origin of the war than was previously appreciated (Ginor and Remez, 2007; Cohen, 2007; Aronson, 2009), especially in explaining the interaction between Israel and Egypt. ${ }^{25}$

Aronson (2009) argues that Israel feared Egypt would attempt to use force to delay or end its nuclear program, and interpreted Egyptian troop movements into the Sinai on the eve of the war as a prelude to preventive attack. According to Ginor and Remez (2007), the Soviet Union supported Egypt and was determined to stop the Israeli nuclear program, even flying strike reconnaissance missions over Israel's nuclear facilities and feeding false information to Egypt about Israel's preparations for war in order to incite Egypt to escalate the crisis. For its part, the United States had been pressuring Israel to forego nuclear weapons, and Cohen (2007) claims that Israel feared the US would abandon it if it made its pursuit of weapons unambiguous or otherwise provoked the Arab states. Isolated and threatened, Israel

\footnotetext{
${ }^{25}$ Note, however, that many of the claims made in this new strand of historiography of the 1967 War are controversial among historians. For alternative views, see Popp (2006); Ro'i and Morozov (2008); Laron (2010). Our intent here is not to adjudicate among these views, but to explore the logic of one view and use it to illustrate our model.
} 
launched what it thought was a preemptive attack on Egypt's air forces in order to avert a preventive strike on Dimona.

Our model makes plain the strategic basis for Israel's fears. Both Israel and Egypt had active nuclear weapons programs in 1967. The unilateral acquisition of nuclear weapons by either would have substantially shifted the balance of power: for Israel, the weapons would compensate for its numerical inferiority and lack of strategic depth; for Egypt, they would lessen the relevance of its technological inferiority. In the model's terms, both $p_{10}-p_{00}$ and $p_{01}-p_{00}$ would be large in magnitude. However, Israel's program had been much more successful than Egypt's, and so Israel was much closer to getting the bomb than was Egypt. In the model, $\lambda_{I S R} \gg \lambda_{E G Y}$. Thus, even if Egypt might derive somewhat greater advantage from unilateral possession of nuclear weapons than Israel, the large difference in the likelihoods of acquisition meant that the expected shift in power $\Delta p$ strongly favored Israel. It follows from Proposition 5 that Egypt would face substantial incentives to launch a preventive attack.

Despite the incentives for war when neither state had nuclear weapons, once Israel had acquired them, it did not give serious consideration to attacking Egypt to prevent its duplication of the technology (Fuhrmann and Kreps, 2010). Egypt signed the Treaty on the Non-proliferation of Nuclear Weapons just a year after the war and ceased to pursue nuclear weapons, rendering such an attack pointless. But even if it had continued its program, its difficulty in securing outside assistance and the parlous state of its finances after the war meant that the per-period chance of acquisition would have been very low for a long time (Einhorn, 2004). Thus, according to Proposition 3, Israel would still have had little reason to attack. In short, the incentives for war were greater when neither state had nuclear weapons than when one of them had acquired them.

The model implies, and this example illustrates, a more general danger inherent in the 
diffusion of arms. The spread of an existing military technology to new localities can cause war even before either side has it. It is especially likely to do so when local actors have observed that the technology was highly consequential in other settings, and when differences in outside assistance or technological development make one side much likelier to get the technology first. Both properties held between Egypt and Israel in 1967.

\section{Conclusion}

Secrecy and diffusion of new military technologies remain understudied in the international relations literature. They are important concepts in understanding how changes in the balance of power might lead to international conflict. The existing literature on this topic has mainly focused on perfectly anticipated deterministic shifts in the balance of military capabilities. These models are not adequate in studying the role of secrecy and diffusion of military technologies, as the latter create uncertainties and probabilistic changes in the balance of power. In this paper, we presented a simple model that examines how secrecy and diffusion shape states' bargaining and conflict behavior by changing the balance of power stochastically in a repeated interaction. The model helps explain why some technologies' spread is more war-prone than others, and why in some cases even the possibility of a new technology that no local state yet possesses might create incentives for war. The model also shows that the fear of future wars due to the spread of new technologies can motivate wars in the present.

Parameters in our model capture 1) how likely a new technology is to emerge, indicating the pace of technological progress and the level of technological sophistication in a given period; and 2) how fast new innovations diffuse to other societies, which is a function of the

level of secrecy, as well as the technological development of other states. These parameters 
in turn influence states' expectations about the future balance of military capabilities. We find that war will occur whenever a state expects a large adverse shift in the future balance of power. This differs from Powell $(1999,2009)$, which found that wars would occur immediately prior to large, rapid shifts. Whereas in Powell's models, one would expect a direct causal link between wars and major changes in the balance of power, our model predicts that the two will only be correlated, as the causal link is indirect. In our model, it is not the occurrence of shifts that matters, but players' expectations about shifts.

Our results shed new light on a very important shift in the international balance of power in recent history: the Soviet Union's successful development of nuclear weapons. We assess existing explanations in the literature for the United States' failure to launch a preventive war against the Soviet Union when the US maintained a nuclear monopoly during 194549. We argue that the evidence provided in the literature to support explanations based on material or normative costs of prevention are ambiguous, and that these approaches by themselves can only provide a part of the reason for the lack of prevention. Our alternative approach emphasizes US expectations about the likelihood and timing of the diffusion of nuclear technology to the Soviet Union, and the US preference to delay a preventive strike until the Soviet bomb was close enough to being imminent. Thus, our explanation qualifies and complements the established cost-based explanations in the literature.

Our model indicates that war between two states may occur even when neither state possesses a new technology that has the potential to shift the balance significantly, but one is more likely to acquire it. More strikingly, periods when no one possesses the technology yet might be more war-prone than periods when one state has a monopoly over it. The intuition for this result is that the state less likely to gain access to the new technology might have strong incentives to prevent the more advanced opponent from acquiring the technology. We discussed this possibility in the context of the 1967 Six-Day War and argued that Israel's 
fears about Egypt's intentions to stop the more advanced Israeli nuclear program played a role in the initiation of war.

Stepping back from these particular examples, a broader implication of our work is that competition among the major powers may impose large, indirect negative externalities on the rest of the world, even aside from the direct effects of colonization, imperialism, and intervention. The generation and use of new, consequential military technologies by rich, technologically advanced powers creates new opportunities for arms diffusion, which may in turn disrupt the balance of power among weaker states and so cause preventive wars. The spread of firearms, invented in China but developed to fearsome effect by the competing European powers, contributed to the causes of wars in the pre-colonial world, and it may still do so today as ever more sophisticated firearms are introduced to less-developed places. And the spread of nuclear weapons, invented to end yet another competition among major powers, contributed to wars in the Middle East and may lead to other wars if proliferation continues.

These externalities can be exacerbated by the willing transfer of military arms, supplies and know-how from advanced countries to other states or groups. Israel's nuclear program was accelerated thanks to help from France, and Pakistan had help from China. The United States and Soviet Union routinely helped third-world states obtain advanced conventional arms. The existing literature on the statistical relationship between (conventional) arms transfers and conflict provides mixed empirical results (Craft and Smaldone, 2002, 2003; Suzuki, 2007), and scholars note a disconnect between the theory driving these studies and the literature on war and bargaining (Krause, 2004). ${ }^{26}$

The comparative statics derived from our analysis help bridge this gap by providing testable hypotheses about the effects of such transfers. They suggest that the characteristics

\footnotetext{
${ }^{26}$ We are not aware of any analysis of the link between nuclear weapons assistance and conflict.
} 
of these transfers will influence the receiving states' involvement in conflict. First, when the potential belligerents see a higher probability of outside intervention, the incentives for the player most likely to be harmed by the intervention to launch a preventive attack increase. For instance, the entry into negotiations over arms packages by one side may raise the probability of a shift and thereby lead to an attack by the other. Similarly, when arms transfers are occurring regularly, sharp discord between the supported player and its external patron may lead to an increased expectation that the transfers will soon be halted, encouraging the client to fight now to lock in its current advantage.

Second, the higher the impact of the anticipated transfers on the prior balance, the more risk there is of war. For instance, a situation in which one belligerent of modest technological sophistication anticipated transfers from a superpower would be more prone to preventive war than one in which the external actor was another state of modest development. Similarly, if one belligerent has become highly dependent on external support for its military, the incentives for preventive attack if this support might someday evaporate are higher than if the external support was merely ancillary.

Our analysis yields two recommendations for a powerful state that wishes to avoid causing wars with its arms transfers. First, if a change in the quantity and quality of arms transfers is desired, it should be implemented slowly, so that discounting lessens the commitment problem. Second, signals of future changes in arms transfers should be concealed to the extent possible, so that the party that will be harmed by a shift will not anticipate it and so will have less incentive to launch a preventive war. Third, if the other side also has a patron, alterations in the quality and quantity of its arms transfers should be matched closely, if possible, to minimize shocks to the balance of power. 


\section{References}

Aronson, Shlomo. 2009. "David Ben-Gurion, Levi Eshkol and the Struggle over Dimona: A Prologue to the Six-Day War and its (Un) Anticipated Results." Israel Affairs 15(2):114134.

Baliga, Sandeep and Tomas Sjöström. 2008. "Strategic Ambiguity and Arms Proliferation." Journal of Political Economy 116(6):1023-1057.

Belich, James. 1996. Making Peoples: A History of the New Zealanders from Polynesian Settlements to the End of the Nineteenth Century. Auckland, New Zealand: Penguin Press.

Binmore, Ken, Ariel Rubinstein and Asher Wolinsky. 1986. "The Nash Bargaining Solution in Economic Modelling." RAND Journal of Economics 17(2):176-188.

Buhite, Russell D. and Wm. Christopher Hamel. 1990. "War for Peace: The Question of an American Preventive War against the Soviet Union, 1945-1955." Diplomatic History 14(3):367-384.

Cohen, Avner. 2007. "Crossing the Threshold: The Untold Nuclear Dimension of the 1967 Arab-Israeli War and Its Contemporary Lessons." Arms Control Today 37(5).

Copeland, Dale C. 2000. The Origins of Major War. Cornell University Press.

Craft, Cassady and Joseph P. Smaldone. 2002. "The Arms Trade and the Incidence of Political Violence in Sub-Saharan Africa, 1967-97." Journal of Peace Research 39(6):693710.

Craft, Cassady and Joseph Smaldone. 2003. "Arms Imports in Sub-Saharan Africa: Predicting Conflict Involvement." Defence and Peace Economics 14(1):37-49.

Crosby, Ron D. 1999. The Musket Wars. Auckland, New Zealand: Reed Books.

Debs, Alexandre and Nuno Monteiro. 2010. "Nothing to Fear but Fear Itself? Nuclear Proliferation and Preventive War." Unpublished typescript.

Einhorn, Robert J. 2004. Egypt: Frustrated but Still on a Non-Nuclear Course. In The Nuclear Tipping Point, ed. Kurt M. Campbell, Robert J. Einhorn and Mitchell B. Reiss. Washington, DC: Brookings Institution Press pp. 43-82.

Fearon, James D. 1995. "Rationalist Explanations for War." International Organization 49(03):379-414.

Fuhrmann, Matthew and Sarah E. Kreps. 2010. "Targeting Nuclear Programs in War and Peace: A Quantitative Empirical Analysis, 1941-2000." Journal of Conflict Resolution . Forthcoming. 
Ginor, Isabella and Gideon Remez. 2007. Foxbats over Dimona: The Soviets' Nuclear Gamble in the Six-Day War. Yale University Press.

Gordin, Michael D. 2009. Red Cloud at Dawn: Truman, Stalin, and the End of the Atomic Monopoly. Farrar, Straus, and Giroux.

Horowitz, Michael C. 2010. The Diffusion of Military Power: Causes and Consequences for International Politics. Princeton University Press.

Jackson, Matthew O. and Massimo Morelli. 2009a. "The Reasons for Wars: An Updated Survey." Forthcoming in The Handbook on the Political Economy of War, edited by Chris Coyne, Elgar Publishing.

Jackson, Matthew O. and Massimo Morelli. 2009b. "Strategic Militarization, Deterrence and Wars." Quarterly Journal of Political Science 4:279-313.

King, Michael. 1997. 1000 Years of Maori History. Auckland, New Zealand: Reed Books.

Krause, Volker. 2004. "Hazardous Weapons? Effects of Arms Transfers and Defense Pacts on Militarized Disputes, 1950-1995." International Interactions 30(4):349-371.

Laron, Guy. 2010. "Playing with Fire: The Soviet-Syrian-Israeli Triangle, 1965-1967." Cold War History 10(2):163-184.

Levy, Jack S. 1987. "Declining Power and the Preventive Motivation for War." World Politics 40(1):82-107.

Levy, Jack S. 2008. "Preventive War and Democratic Politics." International Studies Quarterly 52(1):1-24.

Meirowitz, Adam and Anne Sartori. 2008. "Strategic Uncertainty as a Cause of War." Quarterly Journal of Political Science 3:327-352.

Pool, D. Ian. 1977. The Maori Population of New Zealand, 1769-1971. Auckland, New Zealand: Auckland University Press.

Pool, D. Ian. 1991. Te Iwi Maori: A New Zealand Population, Past, Present E Projected. Auckland, New Zealand: Auckland University Press.

Popp, Roland. 2006. "Stumbling Decidedly into the Six-Day War." Middle East Journal 60(2):281-309.

Posen, Barry R. 1984. The Sources of Military Doctrine: France, Britain, and Germany Between the World Wars. Cornell University Press.

Powell, Robert. 1993. "Guns, Butter, and Anarchy." The American Political Science Review 87(1):115-132. 
Powell, Robert. 1999. In the Shadow of Power: States and Strategies in International Politics. Princeton University Press.

Powell, Robert. 2004. "The Inefficient Use of Power: Costly Conflict with Complete Information." American Political Science Review 98(2):231-241.

Powell, Robert. 2006. "War as a Commitment Problem." International Organization 60:169203.

Powell, Robert. 2009. "Persistent Fighting to Forestall Adverse Shifts in the Distribution of Power." Unpublished typescript.

Quester, George H. 2000. Nuclear Monopoly. Transaction Publishers.

Richelson, Jeffrey T. 2007. Spying on the Bomb: American Nuclear Intelligence from Nazi Germany to Iran and North Korea. W. W. Norton.

Ro'i, Yaacov and Boris Morozov, eds. 2008. The Soviet Union and the June 1967 Six Day War. Stanford University Press.

Rosen, Stephen Peter. 1991. Winning the Next War: Innovation and the Modern Military. Cornell University Press.

Rubinstein, Ariel. 1982. "Perfect Equilibrium in a Bargaining Model." Econometrica 50(1):97-109.

Silverstone, Scott A. 2007. Preventive War and American Democracy. Routledge.

Suzuki, Susumu. 2007. "Major Arms Imports and the Onset of Civil and Ethnic Wars in the Postcolonial World, 1956-1998: A Preliminary Reassessment." The Social Science Journal 44(1):99-111.

Taylor, A.J.P. 1954. The Struggle for Mastery in Europe, 1848 to 1918. Clarendon Press.

Trachtenberg, Marc. 1988. "A 'Wasting Asset': American Strategy and the Shifting Nuclear Balance, 1949-195." International Security 13(3):5-49.

Trachtenberg, Marc. 2007. "Preventive War and US Foreign Policy." Security Studies 16(1):1-31. 


\section{A Appendix}

\section{A.1 Proof of Proposition 1}

Proof. The proof has three steps. First, we demonstrate that no war can occur in an SPE. Second, we show that there can be no revisions if $q \in\left[p_{11}-c_{A}, p_{11}+c_{B}\right]$. Finally, we show that any $q$ outside this range is immediately and permanently revised to the nearer endpoint of the range.

Suppose by way of contradiction that there is an SPE that features war. In the period in which war will occur, the players' equilibrium continuation values are $W_{11}^{A}=\frac{p_{11}-c_{A}}{1-\delta}$ and $W_{11}^{B}=\frac{1-p_{11}-c_{B}}{1-\delta}$. Observe that if the status quo settlement or an offered revision $q \in$ $\left(p_{11}-c_{A}, p_{11}+c_{B}\right)$ were accepted instead, then both players would receive more in this period than they would from war. If this settlement were accepted, each player could assure that his continuation value in any future round was at least his war value, by rejecting or not offering any revision - the worst that could happen is that the other player would attack, giving both their war values. Thus subgame-perfection requires that the offer-receiving player in this round be willing to accept such a $q$. But then the offer-making player could do strictly better than his equilibrium continuation value by offering such a $q$, so war cannot occur in equilibrium.

This implies that an SPE of this subgame consists of a sequence of accepted settlements $\left\{q_{0}^{*}, q_{1}^{*}, \ldots\right\}$. We next show that this sequence must be stationary, that is, that $q_{i}^{*}=q_{j}^{*}$ for all $i, j$, so that there is at most one revision: from $q$ to $q_{0}^{*}$.

Observe that, for any $t$, if $q_{t}^{*} \in\left[p_{11}-c_{A}, p_{11}+c_{B}\right]$, then $A$ 's continuation value must be equal to $q_{t}^{*} /(1-\delta)$. If it is less than this, then $A$ has a profitable deviation wherein $A$ neither offers nor accepts any revision to $q_{t}^{*}$ in any future period, and by subgame perfection $B$ tolerates this deviation because it gives him a continuation value at least equal to his war value. ${ }^{27}$ If instead $A^{\prime}$ 's continuation value is greater than $q_{t}^{*} /(1-\delta)$, then the situation is reversed and $B$ has a profitable deviation analogous to $A$ 's.

Now, if there is some $t$ for which $q_{t}^{*} \in\left[p_{11}-c_{A}, p_{11}+c_{B}\right]$ and $q_{t}^{*} \neq q_{t+1}^{*}$, then the player whose share will be reduced in the transition from $t$ to $t+1$ should not agree to the change. Thus, if the sequence of accepted settlements ever enters this range, no further changes can occur. In particular, if the original status quo $q$ is in this range, there will be no revisions in equilibrium.

So suppose that $q>p_{11}+c_{B}$. Notice that $A$ could obtain a continuation value of $\frac{p_{11}+c_{B}}{1-\delta}$ by offering or accepting a revision to $p_{11}+c_{B}$ at the first opportunity and then agreeing to no further revisions. $B$ would have no choice but to tolerate this revision: it is better than

\footnotetext{
${ }^{27} B$ could choose to attack when indifferent between war and the settlement, but then $A$ 's profitable deviation would entail making or accepting a revision slightly more generous to $B$ at the first opportunity, which $B$ would strictly prefer, and then neither accepting nor offering any further revisions. We subsequently will ignore such indifference cases when they do not affect the substance of our results.
} 
war, and delay would only make $B$ worse off. If, for any $t, q_{t}^{*}<p_{11}-c_{A}$, then $B$ would have an analogous option, which would leave $A$ with a continuation value of at most $\frac{p_{11}-c_{A}}{1-\delta}$, so $A$ would never offer or accept a revision in the range $\left(0, p_{11}+c_{B}\right)$. Since, by the first step in the proof, war cannot occur in equilibrium, $B$ 's continuation value in the first period must be at least his war value, $\frac{1-p_{11}-c_{B}}{1-\delta}$. Since revisions to something less than $p_{11}+c_{B}$ are unacceptable to $A$, this implies that $q_{0}^{*}$ must be equal to $p_{11}+c_{B}$.

A similar argument for the case when $q<p_{11}-c_{A}$ completes the proof.

The continuation values for $A$ and $B$ of this subgame, as a function of the status quo settlement $q$, follow immediately from Proposition 1, and will be used in the proofs of the other propositions. They are:

$$
\begin{gathered}
V_{11}^{A}(q)= \begin{cases}\frac{p_{11}-c_{A}}{1-\delta} & \text { if } q \leq p_{11}-c_{A} \\
\frac{q}{1-\delta} & \text { if } p_{11}-c_{A}<q<p_{11}+c_{B} \\
\frac{p_{11}+c_{B}}{1-\delta} & \text { if } p_{11}+c_{B} \leq q\end{cases} \\
V_{11}^{B}(q)= \begin{cases}\frac{1-p_{11}+c_{A}}{1-\delta} & \text { if } q \leq p_{11}-c_{A} \\
\frac{1-q}{1-\delta} & \text { if } p_{11}-c_{A}<q<p_{11}+c_{B} \\
\frac{1-p_{11}-c_{B}}{1-\delta} & \text { if } p_{11}+c_{B} \leq q\end{cases}
\end{gathered}
$$

Notice that both functions are continuous and (weakly) monotonic in all the variables

\section{A.2 Proof of Proposition 2}

Proof. There are three steps. First, we show that the condition above is sufficient to guarantee war in any SPE. Next, we show that it is also necessary. Finally, we establish that at most one, immediate revision can occur.

Let $W_{10}^{A}=\frac{p_{10}-c_{A}}{1-\delta}$ and $W_{10}^{B}=\frac{1-p_{10}-c_{B}}{1-\delta}$ be the players' continuation values for war in this subgame. Let $V_{10}^{A}(q)$ be the continuation value for player $A$ of a peaceful settlement $q$ that is immediately agreed and lasts until $B$ receives the technology, and $V_{10}^{B}(q)$ similarly for $B$. The former is given by the recursive equation:

$$
\begin{aligned}
V_{10}^{A}(q) & =q+\delta\left[\lambda_{A B} V_{11}^{A}(q)+\left(1-\lambda_{A B}\right) V_{10}^{A}(q)\right] \\
\Rightarrow V_{10}^{A}(q) & =\frac{q+\delta \lambda_{A B} V_{11}^{A}(q)}{1-\delta\left(1-\lambda_{A B}\right)}
\end{aligned}
$$


Similarly, we have:

$$
V_{10}^{B}(q)=\frac{1-q+\delta \lambda_{A B} V_{11}^{B}(q)}{1-\delta\left(1-\lambda_{A B}\right)}
$$

Notice that $V_{10}^{A}(1)$ is the maximum continuation value that $A$ could possibly receive starting from the diffusion subgame. It entails $B$ conceding the whole stake to $A$ in the current period, and in every subsequent period until $B$ receives the technology, at which point the outcome is as prescribed by Proposition 1. If $V_{10}^{A}(1)<W_{10}^{A}$, then there is no way $A$ can be satisfied in this subgame, so $A$ will immediately attack in any SPE. Substituting the value of $V_{11}^{A}(1)$ from (2) into (5) and rearranging this inequality, we obtain the condition for war given in the proposition, and sufficiency is proven.

To see necessity, suppose that $V_{10}^{A}(1) \geq W_{10}^{A}$. We will show that this implies the existence of a settlement that both players would prefer to war. First observe that:

$$
V_{10}^{A}(0)=\frac{\delta \lambda_{A B} V_{11}^{A}(q)}{1-\delta\left(1-\lambda_{A B}\right)}=\frac{\delta \lambda_{A B}\left(p_{11}-c_{A}\right)}{(1-\delta)\left(1-\delta\left(1-\lambda_{A B}\right)\right)}<\frac{p_{11}-c_{A}}{1-\delta}<\frac{p_{10}-c_{A}}{1-\delta}=W_{10}^{A}
$$

Next notice from (5) that $V_{10}^{A}$ is continuous and strictly increasing in $q$. If the value of this function is (weakly) above $W_{10}^{A}$ at $q=1$ and below it at $q=0$, then by the Intermediate Value Theorem there must be some $q^{*} \in[0,1]$ such that $V_{10}^{A}\left(q^{*}\right)=W_{10}^{A}$. Finally, observe that:

$$
V_{10}^{A}(q)+V_{10}^{B}(q)=\frac{1+\delta \lambda_{A B}\left[V_{11}^{A}(q)+V_{11}^{B}(q)\right]}{1-\delta\left(1-\lambda_{A B}\right)}=\frac{1+\delta \lambda_{A B}\left[\frac{1}{1-\delta}\right]}{1-\delta\left(1-\lambda_{A B}\right)}=\frac{1}{1-\delta}
$$

This implies that $V_{10}^{B}\left(q^{*}\right)=\frac{1}{1-\delta}-W_{10}^{A}=\frac{1-p_{10}+c_{A}}{1-\delta}>\frac{1-p_{10}-c_{B}}{1-\delta}=W_{10}^{B}$. Thus, both $A$ and $B$ would prefer settling at $q^{*}$ to war.

Since $V_{10}^{B}$ is continuous and strictly decreasing in $q$, the same arguments as in the proof of Proposition 1 can be used to show that war cannot occur, and that the unique equilibrium outcome has at most one revision, which is made immediately.

It is easy to derive the continuation values of this game for both players, as a function of the status quo $q$. If the condition in Proposition 2 is met, the players receive their war 
values. Otherwise, their values are:

$$
\begin{aligned}
& V_{10}^{A}(q)= \begin{cases}\frac{p_{10}-c_{A}}{1-\delta} & \text { if } q \leq q^{*} \\
\frac{q}{1-\delta} & \text { if } q^{*}<q \leq p_{11}+c_{B} \\
\frac{q+\delta \lambda_{A B} \frac{p_{11}+c_{B}}{1-\delta}}{1-\delta\left(1-\lambda_{A B}\right)} & \text { if } p_{11}+c_{B}<q<q^{* *} \\
\frac{p_{10}+c_{B}}{1-\delta} & \text { if } q^{* *} \leq q\end{cases} \\
& V_{10}^{B}(q)= \begin{cases}\frac{1-p_{10}+c_{A}}{1-\delta} & \text { if } q \leq q^{*} \\
\frac{1-q}{1-\delta} & \text { if } q^{*}<q \leq p_{11}+c_{B} \\
\frac{1-q+\delta \lambda_{A B} \frac{1-p_{11}-c_{B}}{1-\delta}}{1-\delta\left(1-\lambda_{A B}\right)} & \text { if } p_{11}+c_{B}<q<q^{* *} \\
\frac{1-p_{10}-c_{B}}{1-\delta} & \text { if } q^{* *} \leq q\end{cases}
\end{aligned}
$$

Here $q^{*}$ is defined, uniquely since $V_{11}^{A}$ is continuous and strictly increasing in $q$, by:

$$
\frac{q^{*}+\delta \lambda_{A B} V_{11}^{A}\left(q^{*}\right)}{1-\delta\left(1-\lambda_{A B}\right)}=W_{10}^{A}
$$

That is, $q^{*}$ is the lowest share of the contested stake that $A$ would prefer taking over going to war. Similarly, $q^{* *}$ is the settlement at which $B$ would be indifferent between war and peace, and is uniquely defined by:

$$
\frac{1-q^{* *}+\delta \lambda_{A B} V_{11}^{B}\left(q^{* *}\right)}{1-\delta\left(1-\lambda_{A B}\right)}=W_{10}^{B}
$$

Both functions are continuous and strictly monotonic in $q$. We will these values to induce the equilibria for the prior subgame in which neither player has the technology.

\section{A.3 Proof of Proposition 4}

Proof. Observe first that for $t \geq n, \lambda_{t}$ is constant, so the game is identical to the subgame analyzed in the previous section and the claim follows immediately from Proposition 2 . We next prove by induction that the maximum value $A$ can obtain from peace in equilibrium is strictly decreasing in $t$ up to period $n$; since $A$ 's value from war does not change prior to $B$ acquiring the technology, the claim follows.

By arguments like those in the proof of Proposition 2, the best $A$ can do from peace in equilibrium is to receive the whole stake until $B$ gets the technology, after which $A$ 's value is determined by Proposition 1 . The value of this at time $t \in\{0, \ldots, n-1\}$ is defined by 
the following set of simultaneous recursive equations:

$$
\left\{V_{t}^{A}(1)=1+\delta\left[\lambda_{t} V_{11}^{A}(1)+\left(1-\lambda_{t}\right) \max \left\{W_{10}^{A}, V_{t+1}^{A}(1)\right\}\right]\right\}_{t \in\{0, \ldots, n-1\}}
$$

with boundary condition $V_{n}^{A}(1)=\frac{1+\delta \lambda_{n} V_{11}^{A}(1)}{1-\delta\left(1-\lambda_{n}\right)}$, taken from Proposition 2.

First we show that $V_{n}^{A}(1)<V_{n-1}^{A}(1)$. Re-arranging (13) using the boundary condition, we have:

$$
V_{n-1}^{A}(1) \geq V_{n}^{A}(1)+\frac{\delta\left(\lambda_{n}-\lambda_{n-1}\right)\left[1-(1-\delta) V_{11}^{A}(1)\right]}{1-\delta\left(1-\lambda_{n}\right)}
$$

Because $V_{11}^{A}(1)<\frac{1}{1-\delta}$, the second term on the right-hand side is strictly positive and so $V_{n}^{A}(1)<V_{n-1}^{A}(1)$. This establishes the base case. For the induction step, we assume that $V_{i+1}^{A}(1)<V_{i}^{A}(1)$ and show that this implies that $V_{i}^{A}(1)<V_{i-1}^{A}(1)$. We have:

$$
\begin{aligned}
\Delta_{i}=V_{i-1}^{A}(1)-V_{i}^{A}(1) & =\delta\left[\lambda_{i-1} V_{11}^{A}(1)+\left(1-\lambda_{i-1}\right) \max \left\{W_{10}^{A}, V_{i}^{A}(1)\right\}\right] \\
& -\delta\left[\lambda_{i} V_{11}^{A}(1)+\left(1-\lambda_{i}\right) \max \left\{W_{10}^{A}, V_{i+1}^{A}(1)\right\}\right]
\end{aligned}
$$

There are four cases to consider, arising from the maxima in (15):

1. Both maxima are equal to $W_{10}^{A}$. Then (15) simplifies to $\delta\left(\lambda_{i}-\lambda_{i-1}\right)\left[W_{10}^{A}-V_{11}^{A}(1)\right]$, which is positive since $\lambda_{i}>\lambda_{i-1}$ and $W_{10}^{A}-V_{11}^{A}(1)=\frac{p_{10}-c_{A}-p_{11}-c_{B}}{1-\delta}>0$ under the supposition given in the proposition.

2. The maxima are $V_{i}^{A}(1)$ and $V_{i+1}^{A}(1)$. Using the induction supposition that $\Delta_{i+1}>0$, it follows that $\Delta_{i}>\delta\left(\lambda_{i}-\lambda_{i-1}\right)\left[V_{i+1}^{A}(1)-V_{11}^{A}(1)\right]$, which is positive since $V_{i+1}^{A}(1) \geq$ $W_{10}^{A}>V_{11}^{A}(1)$.

3. The maxima are $V_{i}^{A}(1)$ and $W_{10}^{A}$. It follows that $\Delta_{i}>\delta\left(\lambda_{i}-\lambda_{i-1}\right)\left[W_{10}^{A}-V_{11}^{A}(1)\right]$, which is positive by Case 1 .

4. The maxima are $V_{i+1}^{A}(1)$ and $W_{10}^{A}$. This contradicts the induction supposition that $\Delta_{i+1}>0$.

\section{A.4 Proof of Proposition 5}

Proof. We begin by calculating the continuation value for $A$ of an immediately agreed settlement $q$ that lasts until a player receives the technology, as follows:

$$
\begin{aligned}
V_{00}^{A}(q) & =q+\delta\left[\left(1-\lambda_{A}\right)\left(1-\lambda_{B}\right) V_{00}^{A}(q)+\lambda_{A}\left(1-\lambda_{B}\right) V_{10}^{A}(q)+\left(1-\lambda_{A}\right) \lambda_{B} V_{01}^{A}(q)+\lambda_{A} \lambda_{B} V_{11}^{A}(q)\right] \\
\Rightarrow & V_{00}^{A}(q)=\frac{q+\delta\left[\lambda_{A}\left(1-\lambda_{B}\right) V_{10}^{A}(q)+\left(1-\lambda_{A}\right) \lambda_{B} V_{01}^{A}(q)+\lambda_{A} \lambda_{B} V_{11}^{A}(q)\right]}{1-\delta\left(1-\lambda_{A}\right)\left(1-\lambda_{B}\right)}
\end{aligned}
$$


War is certain to occur if its value for $A$ exceeds the best $A$ could possibly obtain from peace, or $W_{00}^{A}=\frac{p_{00}-c_{A}}{1-\delta}>V_{00}^{A}(1)$. Substituting from (16) and re-arranging, we obtain the inequality in the statement of the proposition and sufficiency is proven. Necessity follows from arguments very similar to those used to show necessity in the proof of Proposition 2 .

\section{A.5 Recurring Diffusion with Multiple Technologies}

The model presented in the paper has focused on the role of only one technology that, once acquired, creates a perfectly anticipated shift in the balance of military capabilities. Once both states receive this technology, there are no further changes to the balance of power. We now investigate if our results extend to the case of multiple technologies with varying effects on the balance of power and uncertainty about which technology becomes available next.

To make the analysis tractable, we simplify the bargaining protocol by focusing on a take-it-or-leave-it structure with probabilistically alternating offers. At the beginning of each period, with probability $m$, A makes an offer $\left(x_{t}, 1-x_{t}\right)$ for the division of the pie, and $\mathrm{B}$ can either accept this offer without any revisions, or reject it. With probability 1-m, $B$ makes the offer instead. Rejection of an offer results in war. We still model war as a costly lottery: in any period, the probability that A wins the war is denoted by $p_{t}$, and B's probability is $1-p_{t}$.

We consider the effect of shifts in $p_{t}$ due to the diffusion of new technologies on states' conflict behavior. Assume that, in the beginning of each bargaining round, with probability $\lambda$, a new technology becomes available to one or both players the balance parameter $p_{t}$ changes. More formally, with probability $\lambda$, Nature draws $p_{t}$ from a continuous probability distribution function $f\left(p_{t}\right)$, defined over $p_{t} \in[0,1]$ with mean $p$ and cumulative distribution function $F\left(p_{t}\right)$, which is continuous and strictly increasing. We refer to $p$ as the "long term balance" parameter.

We restrict our attention to stationary subgame perfect equilibria (SSPE) in which states' strategies only depend on the balance parameter and who makes the offer in a given period. In any peaceful round of a SSPE, the state making the offer makes the minimum feasible offer that gives the other side at least its war payoff. Second, in any SSPE, states use simple cutpoint strategies to attack that are conditional on the balance of power parameter. The attacking decision is monotonic in $p_{t}$ : if a state attacks for a given $p_{t}$, the state also attacks for any $p_{t}^{*}$ that makes the state stronger. Third, the order of play in a given bargaining round does not affect states' equilibrium cutpoints for fighting in an SSPE. ${ }^{28}$

The SSPE will be characterized by four cutpoints:

- $\underline{p}$ represents the balance parameter at which $\mathrm{B}$ is indifferent between accepting the

\footnotetext{
${ }^{28}$ We do not provide the proofs of these results for space reasons. They are available from the authors upon request.
} 
whole pie versus rejecting it and going to war. Below this cutpoint, B will require an offer giving $\mathrm{B}$ more than the whole pie, which is not feasible, and war will result.

- $p_{B}^{*}$ is relevant when $\mathrm{B}$ is making the first offer. At this cutpoint, $\mathrm{B}$ receives the whole pie, and all the efficiency gain from avoiding war goes to B. Between this cutpoint and $p$, B is still willing to avoid war by accepting the whole pie, but some of the surplus from avoiding war goes to A.

- $p_{A}^{*}$ is relevant when Nature chooses A to make the first offer. At this cutpoint, A receives the whole pie, and all the efficiency gain from avoiding war goes to A. Between this cutpoint and $\bar{p}$, A is still willing to avoid war by accepting the whole pie, but some of the surplus from avoiding war goes to B.

- At $\bar{p}, \mathrm{~A}$ is indifferent between receiving the whole pie or going to war. At this cutpoint, $\mathrm{B}$ receives the whole efficiency gain. When $p_{t}>\bar{p}, \mathrm{~A}$ prefers war in equilibrium.

The cutpoints $p$ and $\bar{p}$, are illustrated in Figure 2, where the balance parameter is drawn from a unimodal distribution. As the figure shows, for small enough $p_{t}$, B cannot be bought off in equilibrium, and for large enough $p_{t}$, A prefers attacking to accepting $x=1$. In other words, it is preferable for states to take advantage of a favorable balance of capabilities by attacking the other side and thereby ending the game.

Assuming that both players attack for some values of $p_{t}$ in equilibrium, the equilibrium cutpoints must satisfy the following system of equations: ${ }^{29}$

$$
\begin{aligned}
\frac{1+\delta \lambda\left(\frac{1-p-c_{B}}{1-\delta}+m S_{A}+(1-m)\left(Q P-S_{B}\right)\right)}{1-\delta(1-\lambda)} & =\frac{1-\underline{p}-c_{B}}{1-\delta} \\
\frac{1+\delta \lambda\left(\frac{1-p-c_{B}}{1-\delta}+m S_{A}+(1-m)\left(Q P-S_{B}\right)\right)}{1-\delta(1-\lambda)} & =E(V)-\frac{p_{B}^{*}-c_{A}}{1-\delta} \\
\frac{1+\delta \lambda\left(\frac{p-c_{A}}{1-\delta}+m\left(Q P-S_{A}\right)+(1-m) S_{B}\right)}{1-\delta(1-\lambda)} & =E(V)-\frac{1-p_{A}^{*}-c_{B}}{1-\delta} \\
\frac{1+\delta \lambda\left(\frac{p-c_{A}}{1-\delta}+m\left(Q P-S_{A}\right)+(1-m) S_{B}\right)}{1-\delta(1-\lambda)} & =\frac{\bar{p}-c_{A}}{1-\delta}
\end{aligned}
$$

\footnotetext{
${ }^{29}$ The equilibrium conditions when $\underline{p} \leq 0$ or $\bar{p} \geq 1$ can be specified similarly by replacing the war indifference equation for the peaceful player with an inequality and his war cutpoint with 0 (for B) or 1 (for A).
} 
where

$$
\begin{aligned}
P & =F(\bar{p})-F(\underline{p}) \\
Q & =\frac{c_{A}+c_{B}}{1-\delta(1-\lambda(1-(F(\bar{p})-F(\underline{p}))))} \\
E(V) & =\frac{1-c_{A}-c_{B}}{1-\delta}+Q \\
S_{A} & =\int_{p_{A}^{*}}^{\bar{p}} \frac{p_{t}-p_{A}^{*}}{1-\delta} f\left(p_{t}\right) d p_{t} \\
S_{B} & =\int_{\underline{p}}^{p_{B}^{*}} \frac{p_{B}^{*}-p_{t}}{1-\delta} f\left(p_{t}\right) d p_{t} .
\end{aligned}
$$

$P$ is the equilibrium probability of peace. $Q$ is the expected total surplus from avoiding war. This surplus increases as the probability of peace increases in the future. If there is no fighting in equilibrium, $Q=\frac{c_{A}+c_{B}}{1-\delta}$. As the values of $p_{t}$ that make war inevitable become more probably, however, this surplus shrinks. $E(V)$ is the total expected value of the game. If there is no fighting in equilibrium, $E(V)=\sum_{i=1}^{\infty} \delta^{i-1}=\frac{1}{1-\delta} . S_{A}$ is the part of the future surplus $\mathrm{B}$ expects to receive when A makes the first offer. When A is making offers, B receives more than its war payoff only when the balance parameter is between $p_{A}^{*}$ and $\bar{p}$, and when $p_{t}=\bar{p}$, B receives all the efficiency gain from avoiding war. Similarly, $S_{B}$ is the part of the surplus A expects to receive when B makes the offers.

The non-linear system of four equations above, characterizing states' equilibrium cutpoints, does not have a closed-form solution. To show that a SSPE exists, and to evaluate the comparative statics of the parameters of interest, we use computer simulations to find a solution to this system for different combinations of $m, \lambda, \delta, c_{A}$, and $c_{B} \cdot{ }^{30}$

[Figure 2 about here.]

As in our previous model, we find that states' incentives to attack their opponent increase if they view a favorable balance as only temporary. How long the favorable balance will last in expectation is a function of $\lambda$. When $\lambda$ is smaller, states expect a given balance to last for more periods. In contrast, larger $\lambda$ indicates that a favorable $p_{t}$ is only temporary and it is highly likely that in the future periods the balance will shift back to its long-term expectation value $p$. Thus, the range of $p_{t}$ values that result in peace shrinks as $\lambda$ increases. ${ }^{31}$

\footnotetext{
${ }^{30}$ We consider $m=\{0, .1, .5, .9,1\}, \quad \lambda=\{0, .1, .2, \ldots, .9,1\}, \delta=\{.1, .2, \ldots, .8, .9\}, c_{A}=$ $\{0, .025, .05, \ldots, .225, .25\}$, and $c_{B}=\{0, .025, .05, \ldots, .225, .25\}$. We also consider the Uniform and various unimodal and bimodal Beta distributions defined over the $[0,1]$ interval. For each parameter configuration, our simulations find solutions to the nonlinear system of equations using the BB package in R. To check if there are multiple equilibria, we used 150 different random starting vectors for each case. In each parameter specification we considered, our simulations returned a unique solution to the system, suggesting a unique stationary equilibrium. The simulation code and data are available upon request.

${ }^{31}$ Not surprisingly, we find the same comparative statics results on $\delta, c_{A}$, and $c_{B}$. While larger $\delta$ decrease the range of $p_{t}$ that result in peace, larger $c_{A}$ and $c_{B}$ make peace more likely.
} 
The distribution of future shifts plays an important role in the likelihood of conflict. It factors into states' strategies through three mechanisms: first, the mean of the distribution determines the long term balance between the states and whether the balance in a given period is favorable or not compared to the expected balance in the future. Second, the distribution determines how likely war is in the future, and hence the expected total future value of the game. Finally, it also affects how much of the surplus is expected to go to which state during future peaceful rounds. Overall, distributions that make realizations of larger $p_{t}$ more likely represents a more favorable future for A. Thus, draws of $p_{t}$ favorable to B are more likely to induce B to attack, as they represent temporary windows of opportunity for B before an expected shift back to a more favorable balance for $\mathrm{A}$. The commitment problem is more severe in trying to compensate B for unfavorable future rounds. A, in contrast, does not have strong incentives to attack expect perhaps for very high values of $p_{t}$. This is because in the future A expects the balance to stay in his favor.

Finally, the parameter $m$, the probability that Nature chooses A instead of B to make the take-it-or-leave-it offer in a given period, captures the level of bargaining advantage A has over B. Both players prefer making offers during the bargaining rounds, because the player making the offer will try to make the minimum feasible offer that gives the other player at least its war payoff, and keep to himself the rest of the surplus. As $m$ increases, A has more of this advantage. As $m$ increases, both states' cutpoints increase. This is because, with higher $m$, the future is not as favorable to $\mathrm{B}$ and war in this round becomes more attractive. Conversely, A needs more extreme values of $p_{t}$ in this period to initiate a war and forego an expected favorable future. 


\begin{tabular}{c|cccccccc|ccc}
\hline \hline & \multicolumn{7}{|c|}{ Parameter Values } & \multicolumn{3}{c}{ Subgame Outcomes } \\
Case & $\lambda_{A}$ & $\lambda_{B}$ & $\lambda_{A B}$ & $\lambda_{B A}$ & $p_{00}$ & $p_{10}$ & $p_{01}$ & $p_{11}$ & Introduction & $A$ has it & $B$ has it \\
\hline 1 & .1 & .1 & .25 & .25 & .5 & .75 & .25 & .5 & Peace & Peace & Peace \\
2 & .1 & .1 & .2 & .15 & .5 & .9 & .25 & .35 & Peace & War & Peace \\
3 & .1 & .1 & .2 & .2 & .5 & .75 & .1 & .7 & Peace & Peace & War \\
4 & .1 & .1 & .2 & .2 & .5 & .9 & .1 & .5 & Peace & War & War \\
5 & .1 & .2 & .3 & .25 & .6 & .85 & .15 & .5 & War & War & War \\
6 & .2 & .05 & .25 & .1 & .3 & .8 & .1 & .6 & War & Peace & War \\
7 & .1 & .25 & .3 & .15 & .7 & .8 & .2 & .35 & War & War & Peace \\
8 & .01 & .25 & .3 & .05 & .6 & .9 & .1 & .7 & War & Peace & Peace \\
\hline \hline
\end{tabular}

Table 1: Example Parameter Values and Equilibrium Outcomes in Subgames $\left(\delta=.9, c_{A}=\right.$ $\left.c_{B}=.1\right)$ 


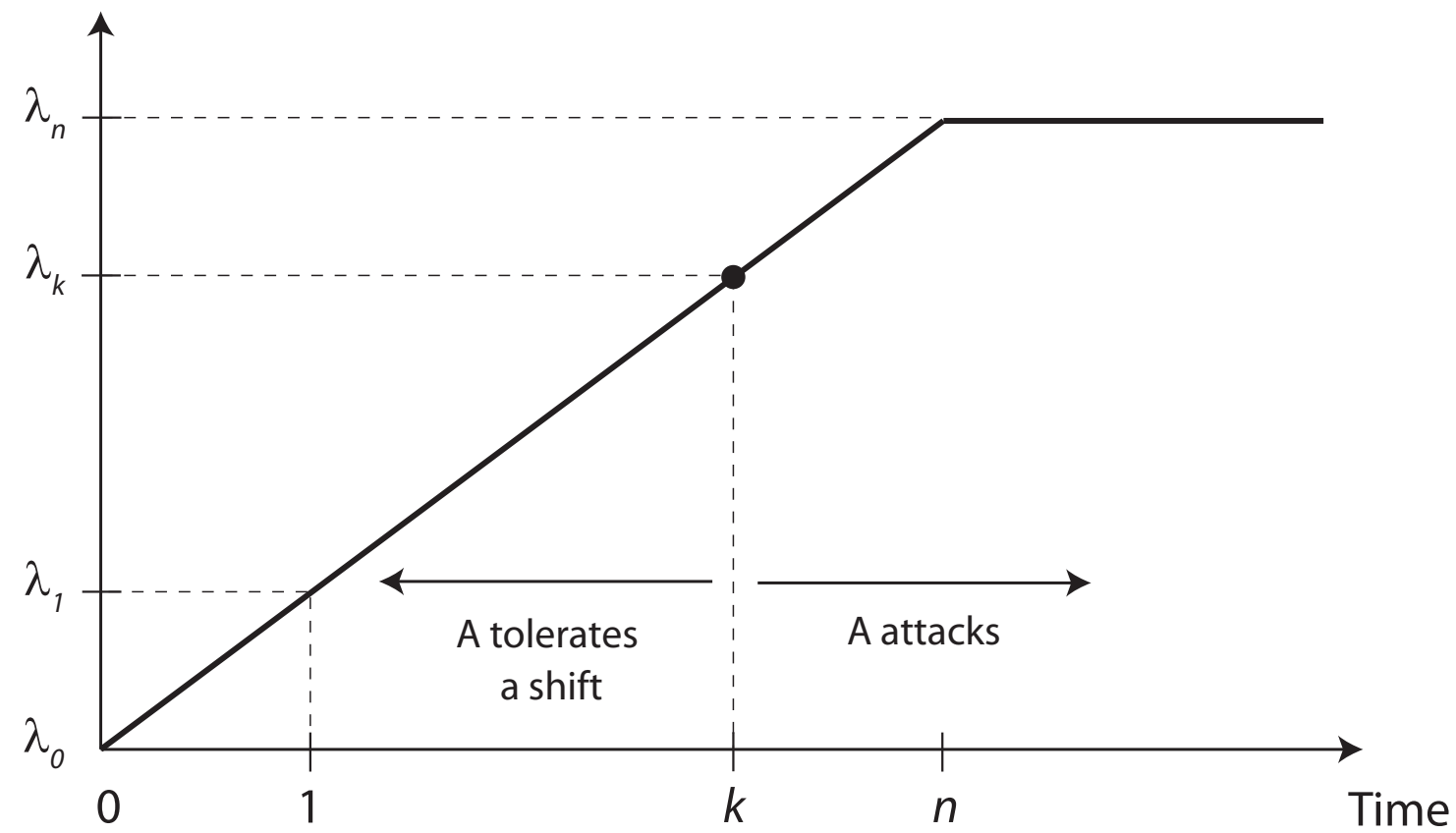

Figure 1: Gradually Increasing $\lambda_{t}$ and Delayed Attack 


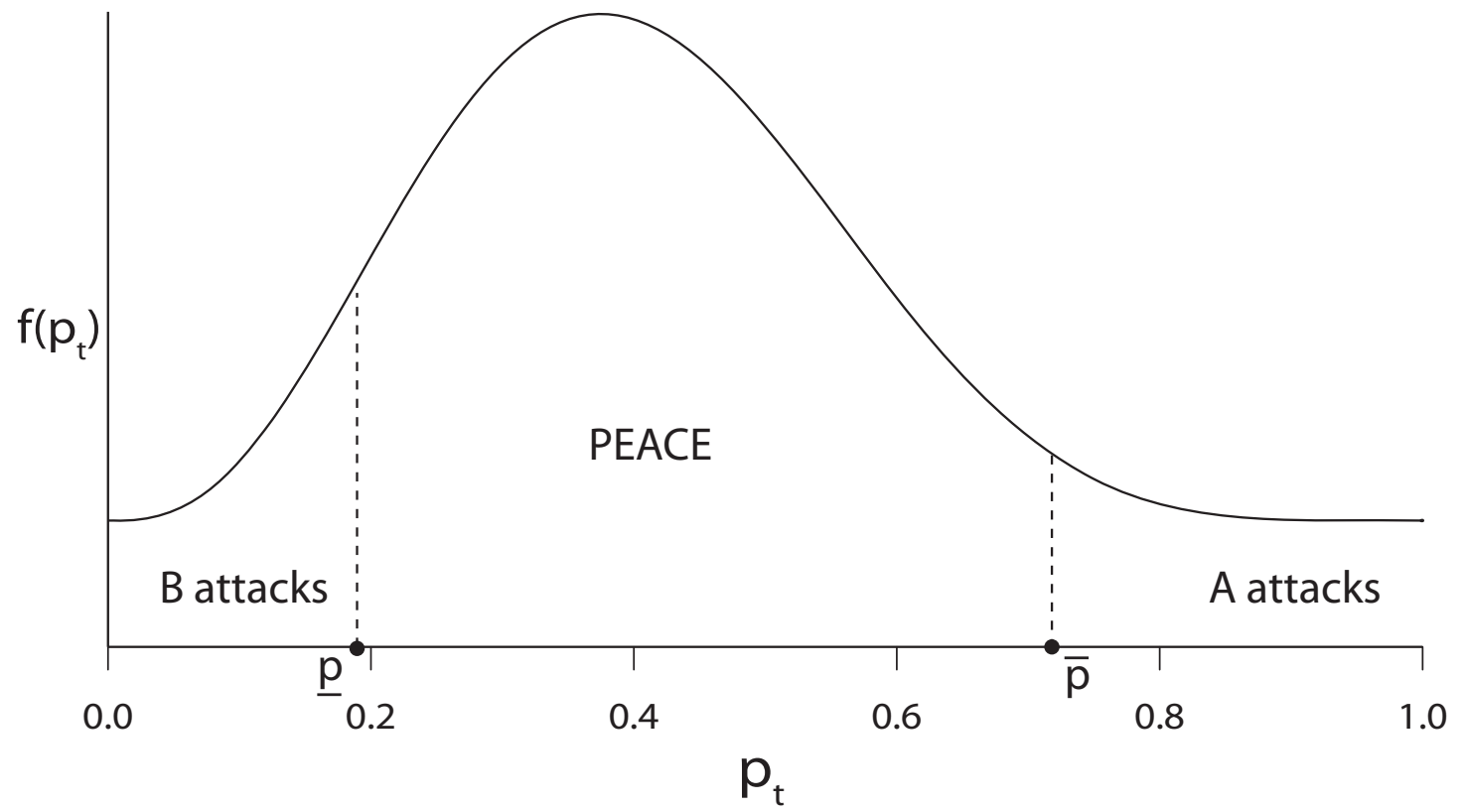

Figure 2: States' Equilibrium Cutpoints in the Recurring Diffusion Model 